\title{
Correlatos afectivos y nivel de conocimientos en el comportamiento sexual de universitarios de Lima*
}

\author{
Manuel Fernández \\ Universidad de Lima \\ Lima, Perú
}

El propósito de esta investigación es describir la relación entre conocimientos y conductas sexuales en universitarios y su vinculación con asertividad, autoestima, control interno afectivo, conducta de riesgo, planificación, organización, toma de decisiones y obediencia. Para ello, 980 estudiantes de ambos sexos, algunos de los cuales cursaban estudios en una universidad nacional y otros en una privada, respondieron una encuesta sobre sexualidad. Se discute la influencia de la familia y el medio ambiente como proveedores de los aspectos afectivos e información sobre la sexualidad y la conducta sexual de los adolescentes y jóvenes universitarios.

Correlatos afectivos / nivel de conocimientos / comportamiento sexual / universitarios

\section{Affective correlate and level of knowledge in the sexual behavior in college students}

The main purpose of the research is to describe the relationship among knowledge about sexuality and some psychological variables as assertivity, self-steem, affective interior control, risk behavior, planning, organization, decision making and obedience to college's students. To explore these variables 980 students, males and females, of a national and a private university answered a Test about sexuality which explored the variables afore mentioned. The influence of the family and the environment is discussed. They provide the affective aspects and information about sexuality and sexual behavior in adolescents college's students.

Affective correlate / level of knowledge / sexual behavior / college students

* Se agradece la colaboración de Beatriz Canessa y Gretna Jugo, alumnas de la Facultad de Psicología de la Universidad de Lima, así como de los profesores Miguel Escurra y Carlos Velásquez, quienes colaboraron en la recolección y procesamiento de datos. 
La sexualidad es un elemento constitutivo de la naturaleza humana, vinculada con la perpetuación de la especie y el desarrollo de la personalidad. Por mucho tiempo sometida a estricto control social y canalizada en la institución del matrimonio, la sexualidad ha comenzado a ser objeto de un sistemático proceso de investigación recién en este siglo (McCary \& McCary, 1980), en el cual se han convertido en populares las encuestas destinadas a obtener información sobre el particular (e.g. Kinsey et al., 1948, 1953; Elmer-Dewill, 1994; Schofield, 1977).

La información en materia de sexualidad es una necesidad no sólo de índole científica; ella responde también a urgencias sociales cada vez más intensas. En una época en la que la salud reproductiva se ha convertido en un tema de atención en la mayoría de las sociedades, la información acerca de actitudes y conductas sexuales constituye un elemento central tanto para la toma de decisiones sociales como para la planificación de políticas educativas sobre este aspecto.

A estas necesidades sociales se ha añadido otra, de dimensiones decisivas en el plano de la salud pública. Nos estamos refiriendo a la necesidad de defenderse frente a la difusión alarmante del sida, que eleva cada vez más sus índices de morbilidad y mortalidad y para el cual aún no se ha logrado encontrar una cura eficaz, así como tampoco estrategias de prevención efectivas. De acuerdo con informaciones periodísticas, en 1997 habían 5 millones 600 mil personas infectadas en el mundo (Time, julio 13, 1998, p. 10).

Una de las urgencias en el desarrollo de políticas educativas y de salud reproductiva es asimismo la obtención de información acerca de actitudes y conductas sexuales de las distintas poblaciones, especialmente adolescente y juvenil (Cáceres et al. 1992; Fernández, 1989). Gracias a ella podremos establecer un banco de datos que permita reconocer conductas de riesgo, grupos humanos proclives a ellas, rasgos de personalidad vinculados con la elevación de dicho riesgo; y, finalmente, a partir de todo ello, emprender acciones que posibiliten un mejor manejo de esta problemática. (Ferrando et al., 1989).

El presente reporte da a conocer los resultados de una investigación efectuada en un grupo de estudiantes universitarios, con el auspicio de la Facultad de Psicología de la Universidad de Lima. La investigación tuvo como propósito hacer un levantamiento de datos acerca de los conocimientos existentes en materia de sexualidad y de la conducta sexual en este grupo de personas, vinculándolos con rasgos de personalidad.

La selección del grupo universitario se debe al hecho evidente de que éste se encuentra conformado en su gran mayoría por personas en los últimos 
años de la adolescencia y los primeros de la juventud, que son asimismo los años en los cuales la sexualidad adquiere mayor importancia en la conducta y en la dinámica psicológica (Giraldo, 1983; McCary \& McCary 1990).

\section{ASPECTOS PSICOLÓGICOS DE LA SEXUALIDAD}

Como ya se ha señalado, la sexualidad es una de las áreas de mayor significado en la vida de las personas. Éste es un hecho reconocido desde muy temprano por todas las sociedades civilizadas que intentan, de una $\mathrm{u}$ otra forma, regular, canalizar y en algunos casos reprimir el impulso sexual.

Desde los estudios de Kinsey (1948, 1953) se ha ido acumulando información acerca de la conducta sexual y sus características. La información ha sido decisiva para el desarrollo de los programas de educación sexual, que son también uno de los productos culturales que este siglo aporta a la humanidad.

En efecto, la mayoría de sociedades se ha despojado del velo de represión y misterio que rodeaban a la sexualidad hasta fines del siglo pasado y, progresivamente, ha adoptado una política mucho más flexible en materia de sexualidad. Así, es frecuente hoy encontrar en periódicos y en revistas reportes acerca de encuestas respecto de la conducta sexual de las personas (e.g. Elmer-Dewill, 1994; León \& Cossío de
Preciado, 1993; Ponce \& La Rosa, 1995). Asimismo, la discusión de temas sexuales y la relativa aceptación de orientaciones sexuales, tales como la homosexualidad, ya no tienen un abierto rechazo (Ferrater Mora \& Cohn, 1981).

Como resultado del desmedido crecimiento demográfico, las altas tasas de embarazo adolescente, el incremento de las enfermedades de transmisión sexual y la aparición del sida y, tras el impacto provocado por éste, las sociedades han creído que uno de los elementos centrales para el desarrollo de estrategias adecuadas es la información. Aunque hay estudios que demuestran que el conocimiento no parece prevenir conductas sexuales de riesgo (Cochran \& Peplau, 1991; Fernández, 1989), de todos modos se considera que sin la variable cognitiva cualquier política de prevención no logrará los efectos esperados.

A pesar de los esfuerzos realizados se observa el conocimiento todavía escaso que muchas personas poseen en materia de sexualidad, lo que expresa el carácter represivo que aún tiene en la sociedad peruana el tratamiento abierto de asuntos acerca del sexo. Es importante además saber cuáles son las fuentes de conocimiento que los adolescentes y jóvenes tienen a su alcance cuando quieren informarse en materia de sexualidad. Algunos estudios reportan por ejemplo que no son los padres sino más bien los amigos los que se 
constituyen en la fuente preferida de información (León \& Cossío de Preciado, 1993; La Rosa, 1997; Ponce \& La Rosa, 1995).

La falta de información sobre la sexualidad afecta las actitudes y conductas sexuales de los adolescentes y los jóvenes. Esta carencia incide significativamente en una serie de problemas psicosociales que se presentan en este grupo etáreo, tales como el embarazo prematuro, el aumento de índices de aborto, matrimonios precoces, inadecuada crianza de los niños, deserción escolar y universitaria, inadecuada organización y planificación de la vida propia y prostitución (La Rosa, 1997).

Pero incide también de otro modo, quizás menos evidente pero de ninguna manera menos importante: la falta de información en materia de sexualidad que afecta el desarrollo de la personalidad de los individuos. Como se anotó al comenzar, la sexualidad es un elemento constitutivo del ser humano. Algunas teorías, como la de Freud, hacen girar toda la estructura de la personalidad y el desarrollo de ésta en torno a la evolución psicosexual de la persona.

La población estudiantil universitaria presenta esta problemática, la misma que suele ser negada por la sociedad, pues erróneamente se asume que por el nivel cultural que poseen, los universitarios no requieren de mayor atención en esta área. Más aún: el universitario mismo considera en muchos casos que él está muy bien informado sobre el particular.

Sin embargo, lo cierto es lo contrario. Quien revise los programas de estudios profesionales de las universidades peruanas observará que en general no hay cursos de educación sexual, salvo en las facultades de educación, ciencias médicas y psicología. Pero aun estos cursos tienen algunas limitaciones severas: la mayoría de ellos sólo enfatiza los aspectos biológicos de la sexualidad, con lo cual toda la problemática social y psicológica permanece ignorada. Esta ignorancia es tanto más llamativa cuando se tiene en cuenta el hecho de que ya hay un cuerpo de información producto de estudios efectuados en el Perú y en América Latina.

Así, por ejemplo, Soto realizó en 1972 una investigación sobre diversos aspectos de actitudes y conductas sexuales en la Universidad de Trujillo, encontrando la presencia de prejuicios sumamente enraizados con relación a la masturbación, percibida por los encuestados como una actividad patológica. El mencionado investigador encontró asimismo que la edad promedio de la iniciación sexual en los varones era de 15.5 años y en las mujeres de 19.9. El uso de anticonceptivos fue reportado como poco frecuente, pero quienes optaban por alguna forma de anticoncepción empleaban predominantemente el preservativo. Uno de cada cinco universitarios reportó al me- 
nos una relación homosexual ocurrida de modo incidental.

En el sur del país, específicamente en la ciudad de Ica, Sevillano llevó a cabo una investigación con 288 estudiantes de la Universidad San Luis Gonzaga, en 1986. Para el efecto utilizó el inventario de Eysenck. Los varones se mostraron más satisfechos y curiosos sexualmente, sin reparos en cuanto a la virginidad para casarse. Ellos disfrutan de las caricias amorosas, no se sienten reprimidos en el terreno sexual y están a favor de la experimentación con el sexo. Las mujeres por su parte afirman presentar dificultades para excitarse, rechazan la pornografía, prefieren la virginidad, tienen vergüenza de hablar de sexo y, por tanto, experimentan sentimientos de culpa sobre el particular.

Fuera del país, en Montevideo, Rostkier (1983) trabajando con universitarios en un curso de educación sexual, encontró que éstos no habían recibido información previa ni por parte del docente ni en el hogar. En México, Cuevas y Wulfert (1983) trabajaron con una muestra de 703 estudiantes de dos universidades de Guadalajara. Tres de cada cuatro hombres y una de cada tres mujeres afirmaron haber tenido relaciones sexuales, la primera de las cuales ocurrió en el caso de los varones en promedio a los 16.9 años, y en las mujeres a los 17.8 años. Dos de cada diez mujeres y cuatro de cada diez hombres sexualmente activos indicaron que no tomaban ninguna medida de contraconcepción. El 21.5\% de mujeres (102) refiere haberse provocado por lo menos un aborto. El nivel de información sexual fue muy bajo y la fuente principal de ella fueron los amigos. Los hombres concedieron mayor importancia a la virginidad femenina que las mujeres.

En Venezuela, Pérez de Gabaldón (1986) trabajó con estudiantes de la Universidad de los Andes, en Mérida, acerca del conocimiento de sexología que ellos tenían, encontrando que los conocimientos previos a un curso sobre sexología eran deficientes.

Chaparro y colaboradores (1987) encontraron en estudiantes de ciencias de la salud en Bogotá, una marcada deficiencia en conocimientos en materia de sexualidad. Resultados similares halló Zaera en 1988, en la Universidad Central de Venezuela, trabajando con 63 estudiantes del ciclo básico de la Facultad de Medicina. A su vez Silva y colaboradores (1988) encontraron en Chile que el nivel de información en materia de métodos anticonceptivos era muy pobre. Los mejores puntajes estaban asociados con el sexo femenino, con estudios de medicina y con el hecho de ser casados.

Acosta y Bernal (1988) realizaron un estudio con 701 estudiantes de la Universidad de Colombia. La finalidad era conocer la actividad sexual y el uso de métodos anticonceptivos. El 69.5\% de los sujetos tenía una vida sexual activa, que se inició más tempranamente en 
los hombres que en las mujeres. Encontraron asimismo una preferencia al menos en el plano declarativo por el uso de anticonceptivos. De los que en efecto usan métodos anticonceptivos encontraron que el $17.5 \%$ había recurrido al aborto, en muchos casos en más de una oportunidad.

Franco (1992), en Buenos Aires, trabajó con estudiantes de medicina (428) y médicos (175) de la capital argentina. Él encontró marcadas fallas en el área de conocimientos sobre sexualidad. Llama la atención en sus resultados que los médicos recién recibidos tienen menos conocimientos o se evalúan menos capacitados en sexualidad, a la inversa de lo que ocurre en otros países. Con referencia a los estudiantes, Franco encontró que más del $50 \%$ de ellos tenía dudas o creía que la masturbación es dañina. En particular la mitad de los ginecólogos y una tercera parte de los urólogos, los psiquiatras y los clínicos, indicaron que la masturbación era causa comprobable de ciertas situaciones de inestabilidad mental y emocional.

Como puede observarse, en la mayoría de los casos reportados por la investigación en el Perú y en América Latina las carencias de información son entendidas como de gran magnitud. La información objetiva y veraz es considerada como un elemento central de toda política planificada y exitosa de educación sexual. Sin embargo, la información por sí sola no basta. Un hallazgo derivado de recientes estudios de psicología de la salud señala que las personas tienden a menospreciar el riesgo de adquirir enfermedades de diversa índole (Rodríguez Marín, 1995).

Esto último tiene que ver con el hecho de que en la conducta de las personas juega un rol decisivo no sólo la información sino también una serie de variables de personalidad, que deben ser tomadas en cuenta. La psicología ha permitido identificar algunas de ellas, como por ejemplo la búsqueda de sensaciones, que fue estudiada en detalle por Zuckerman (1980).

Teniendo en cuenta los cambios que se suscitan en la sociedad con respecto a la sexualidad, así como la problemática que se deriva de ella, nos propusimos llevar a cabo un estudio exploratorio acerca de los conocimientos y conductas sexuales en universitarios. Nos interesó también averiguar qué vinculaciones podrían existir entre la asertividad, la obediencia y otras variables de personalidad, y la conducta sexual.

La asertividad se ha ubicado, desde hace algunos años, en el centro del interés de la psicología clínica. Definida como la capacidad para hacer valer de modo socializado los derechos propios y para expresar de modo apropiado sentimientos y afectos positivos y negativos, la asertividad es considerada una habilidad social decisiva en la vida de las personas.

Como fenómeno psicológico, ella ha sido investigada como realidad per se, pero también a través de realidades 
opuestas a ella, que vendrían a ser la timidez y la ansiedad social.

La investigación sobre el particular ha permitido reconocer que las personas tímidas (que tienen por lo general elevados puntajes en ansiedad social) tienen dificultades para avanzar académicamente, para establecer vínculos amicales estables y variados, y para tener una adecuada relación de pareja.

Así, la capacidad para desarrollar conductas asertivas parece ser un adecuado punto de partida para una vida social más rica, variada y satisfactoria. Cómo se vincula la asertividad con las conductas sexuales fue una de las preguntas que motivó este trabajo.

De un modo amplio, la obediencia puede ser considerada como el polo conductual opuesto a la asertividad. Mientras que la asertividad supone la activa búsqueda del reconocimiento de los propios derechos, la obediencia puede ser entendida como la aceptación acrítica de la normas sociales, más allá de los derechos y sentimientos de las personas.

La obediencia ha sido estudiada desde diferentes ángulos por los psicólogos: Milgram (1974) ha hecho el más conocido de los trabajos; pero los estudios sobre conformidad social pueden también ser considerados.

Personas con elevada obediencia son personas que se distinguirán por patrones actitudinales y conductuales conservadores. Esto, asimismo, debe suceder en el terreno de la conducta sexual.

\section{MATERIAL Y MÉTODO}

\section{Instrumento}

Para la presente investigación se contó con una encuesta y escalas que han sido utilizados en otros trabajos. Específicamente, el instrumento de medición empleado es una adaptación del propuesto por Pick y colaboradores (1988) en su estudio acerca de las características psicosociales de los adolescentes entre 16 y 17 años que han tenido o no relaciones sexuales, realizado en la ciudad de México a través del Instituto Mexicano de Investigación en Familia y Población.

El instrumento consta de 107 ítems de acuerdo con la siguiente estructura (véanse apéndices 1 y 2):

1. Datos generales que se refieren a universidad de procedencia, edad, género $\mathrm{y}$ otros datos familiares $\mathrm{y}$ demográficos.

2. Conocimientos sobre sexualidad, constituida por 21 preguntas objetivas.

3. Aspectos psicológicos conformados por las escalas de asertividad, autoestima, control interno afectivo, conducta de riesgo, planificación, organización, toma de decisiones y obediencia.

En cuanto a la validez y confiabilidad de la prueba de conocimientos, el análisis de ítems se realizó en dos etapas. La primera, con los 21 ítems que conforman la prueba; y, la segunda, sólo con 18 ítems que alcanzaban co- 
rrelación ítem-test corregida igual o superior a .20, los cuales llegan a tener una consistencia interna de .79 .

Con respecto a la dificultad, los ítems que finalmente conforman la escala alcanzan valores entre .49 y .96 , lo cual da una amplitud en la variación de las dificultades. En consecuencia la prueba demuestra ser psicométricamente adecuada para la investigación (véase tabla $\mathrm{N}^{\mathrm{o}}$ 1).

En la tabla $\mathrm{N}^{\circ} 2$ se presentan los análisis de validez y confiabilidad de las di- ferentes escalas psicológicas. Tanto la autoestima como la escala de conducta de riesgo demostraron consistencia en el primer análisis (alfas de .62 y .72, respectivamente). La escala de asertividad requirió de dos análisis; en el primero se eliminó un ítem por baja correlación obteniéndose un alfa de .63; en el segundo, al eliminarse un ítem, el alfa ascendió a .68 .

En lo que respecta al control interno afectivo fue necesario realizar tres análisis: en el primero alcanzó un alfa de

Tabla № 1

Validez y confiabilidad de la prueba de conocimientos

\begin{tabular}{|c|c|c|c|}
\hline ÍTEM & DIFICULTAD & $\begin{array}{l}\text { ANÁLISIS } 1 \\
\text { ritc }\end{array}$ & $\begin{array}{c}\text { ANÁLISIS } 2 \\
\text { ritc }\end{array}$ \\
\hline 1 & .92 & $.22^{*}$ & $.29^{*}$ \\
\hline 2 & .64 & .16 & \\
\hline 3 & .49 & $.28^{*}$ & $.26^{*}$ \\
\hline 4 & .75 & .07 & \\
\hline 5 & .91 & $.34^{*}$ & $.32^{*}$ \\
\hline 6 & .92 & $.24^{*}$ & $.23^{*}$ \\
\hline 7 & .56 & $.28^{*}$ & $.29^{*}$ \\
\hline 8 & .64 & .15 & \\
\hline 9 & .79 & $.24^{*}$ & $.25^{*}$ \\
\hline 10 & .88 & $.28^{*}$ & $.29^{*}$ \\
\hline 11 & .83 & $.23^{*}$ & $.26^{*}$ \\
\hline 12 & .84 & $.25^{\star}$ & $.24^{*}$ \\
\hline 13 & .53 & $.23^{*}$ & $.25^{*}$ \\
\hline 14 & .96 & $.24^{*}$ & $.26^{*}$ \\
\hline 15 & .93 & $.26^{*}$ & $.27^{*}$ \\
\hline 16 & .89 & $.20^{*}$ & $.22^{*}$ \\
\hline 17 & .91 & $.28^{*}$ & $.30^{*}$ \\
\hline 18 & .75 & $.38^{*}$ & $.37^{*}$ \\
\hline 19 & .76 & $.35^{\star}$ & $.36^{*}$ \\
\hline 20 & .95 & $.22^{*}$ & $.21^{*}$ \\
\hline 21 & .58 & $.29^{*}$ & $.33^{*}$ \\
\hline \multicolumn{2}{|c|}{ Kuder Richardson 20} & .69 & .79 \\
\hline
\end{tabular}


.48 , en el segundo se eliminaron dos ítems alcanzándose un alfa de .52 , y en el tercero, en el que se eliminaron tres ítems, se llegó a un alfa de .54.

Los resultados nos permiten afirmar que estas cuatro escalas se adecúan a los requerimientos de la investigación (véase tabla $\mathrm{N}^{\circ} 2$ ).

Finalmente, en la tabla $\mathrm{N}^{\circ} 3$ se observa el análisis de las escalas restantes, observándose que en planificación, organización y obediencia sólo fue necesario ejecutar un análisis, incluyéndose en cada caso todos los items propuestos. La escala más consistente fue la de organización (alfa: .72) seguida por la de planificación (alfa: .70) y obediencia (alfa: .50).

En la escala de toma de decisiones fue necesario realizar dos análisis, el primero arrojó un alfa de .46 y el segundo, después de eliminarse un ítem, ascendió a .56. (véase tabla $\mathrm{N}^{\circ} 3$ ).

En consecuencia, por los resultados señalados, las escalas funcionan en la investigación planteada.

\section{Participantes}

Como resultado de la aplicación se han recolectado 980 encuestas: 491 integrantes de la muestra provenían de la universidad privada, y 489 de la universidad estatal. El total de la muestra estuvo conformado por 534 personas del sexo masculino (54.5\%) y $441 \mathrm{del}$ sexo femenino $(45 \%)$. Cinco participantes $(0.5 \%)$ no informaron acerca de su sexo. En este caso como en otros, un porcentaje mínimo de sujetos dejó de responder algún ítem de la encuesta. El rango de edades de la muestra fue de 16 a 56 años de edad, con una concentración mayor entre 18 y 22 años.

\section{Resultados}

Los resultados se analizarán de acuerdo con dos áreas de trabajo: aspectos demográfico-descriptivos $\mathrm{y}$, aspectos de conducta sexual, relacionados con las variables de personalidad. Por razones de espacio no nos referiremos a todos los ítems, sino más bien haremos una selección de los más importantes para los efectos de este trabajo.

\section{Aspectos demográfico-descriptivos}

En este rubro se consideran los resultados obtenidos de nuestra indagación sobre fuentes de información sexual, educación sexual, condiciones de vida y características de los padres. Esta información es de valor, puesto que permite contextualizar los hallazgos de las secciones posteriores, y a través de esto, obtener una visión de los condicionamientos sociales que influyen en la sexualidad. 
Fernández

Tabla № 2

Validez y confiabilidad de las escalas de asertividad, control interno afectivo, autoestima y conducta de riesgo

\begin{tabular}{|c|c|c|c|c|}
\hline ÍTEM & M & $\begin{array}{l}\text { ANÁLISIS } 1 \\
\text { ritc }\end{array}$ & $\begin{array}{l}\text { ANÁLISIS } 2 \\
\text { ritc }\end{array}$ & $\begin{array}{l}\text { ANÁLISIS } 3 \\
\text { ritc }\end{array}$ \\
\hline \multicolumn{5}{|l|}{ ASERTIVIDAD } \\
\hline 68 & 2.85 & $.44^{\star}$ & $.48^{*}$ & \\
\hline 69 & 3.06 & $.42^{*}$ & $.41^{*}$ & \\
\hline 70 & 2.67 & $.51^{*}$ & $.55^{\star}$ & \\
\hline 71 & 2.98 & $.42^{*}$ & $.45^{\star}$ & \\
\hline 81 & 3.07 & $.31^{*}$ & $.30^{*}$ & \\
\hline 83 & 3.22 & .08 & & \\
\hline Alfa & & .63 & .68 & . \\
\hline \multicolumn{5}{|c|}{ CONTROL INTERNO AFECTIVO } \\
\hline 72 & 2.66 & $.21^{*}$ & $.25^{*}$ & $.26^{*}$ \\
\hline 73 & 2.71 & $.27^{\star}$ & $.32^{*}$ & $.33^{*}$ \\
\hline 74 & 2.46 & $.23^{*}$ & $.29^{*}$ & $.30^{*}$ \\
\hline 75 & 3.04 & $.27^{\star}$ & $.29^{*}$ & $.31^{*}$ \\
\hline 76 & 2.73 & $.20^{*}$ & $.24^{*}$ & $.24^{*}$ \\
\hline 78 & 3.34 & $.24^{*}$ & $.26^{*}$ & $.25^{\star}$ \\
\hline 100 & 3.16 & $.21^{*}$ & & \\
\hline 101 & 2.95 & $.24^{\star}$ & & \\
\hline 102 & 2.88 & $.19^{*}$ & -.00 & \\
\hline Alfa & & .48 & .52 & .54 \\
\hline
\end{tabular}

\begin{tabular}{cll} 
AUTOESTIMA & & \\
84 & 3.08 & $.29^{\star}$ \\
103 & 3.36 & $.43^{\star}$ \\
104 & 2.47 & $.35^{\star}$ \\
105 & 2.96 & $.48^{\star}$ \\
106 & 2.52 & $.36^{\star}$ \\
107 & 3.05 & $.33^{\star}$ \\
\hline Alfa & & .62
\end{tabular}

CONDUCTA DE RIESGO

\begin{tabular}{lll}
94 & 2.52 & $.38^{*}$ \\
95 & 2.78 & $.42^{*}$ \\
108 & 3.53 & $.48^{*}$ \\
110 & 3.54 & $.49^{*}$ \\
111 & 3.76 & $.46^{\star}$ \\
112 & 3.31 & $.43^{*}$ \\
\hline Alfa & & .72
\end{tabular}

${ }^{*}$ ) ítem aceptado

$\mathrm{n}=980$ 
Tabla № 3

Validez y confiabilidad de las escalas de toma de decisiones, planificación, organización y obediencia

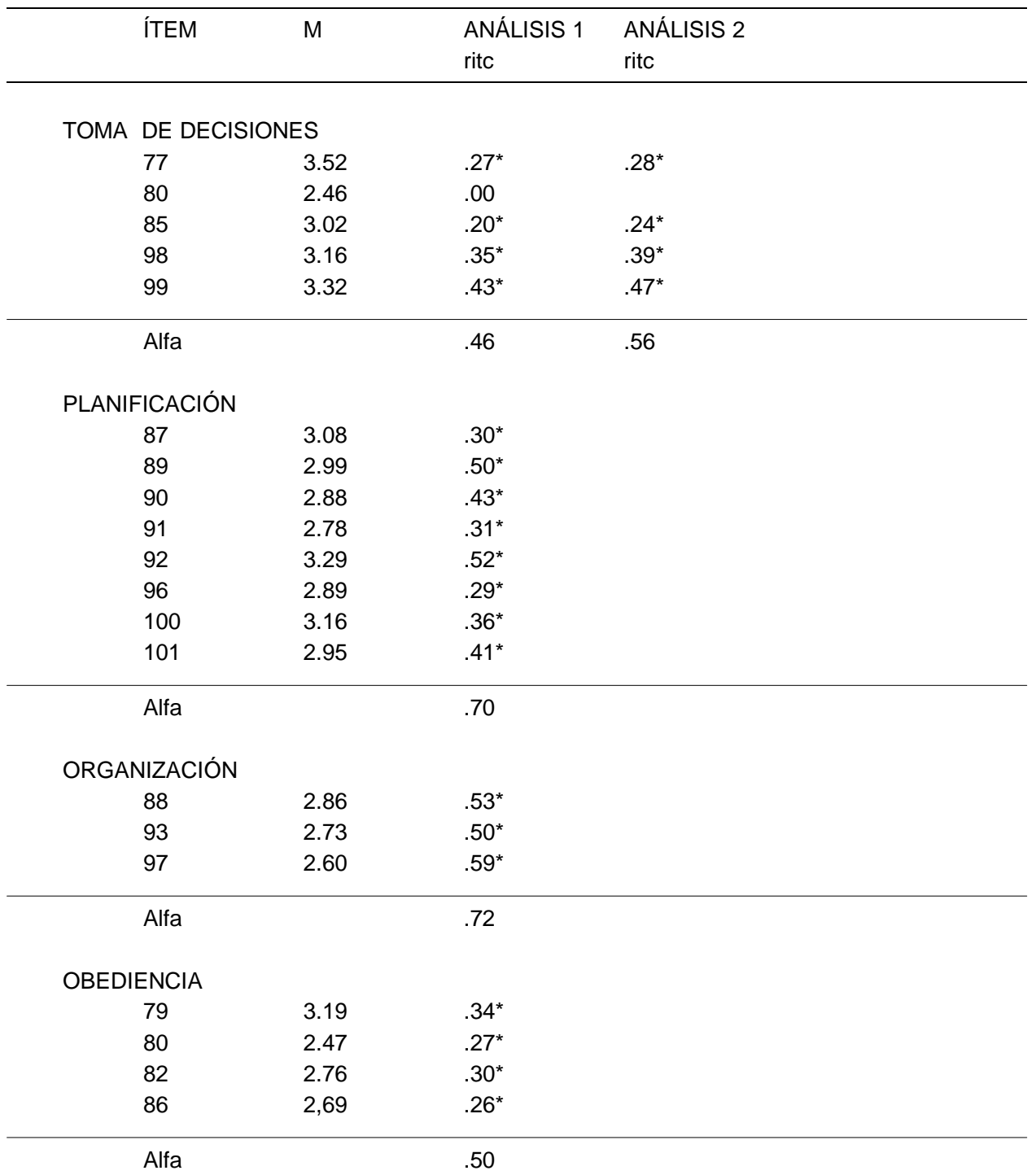

(*) ítem aceptado

$\mathrm{n}=980$ 
La tabla $\mathrm{N}^{\circ} 4$ presenta los porcentajes de personas que han señalado haber recibido información sexual de algunas de las siguientes fuentes: familia, amigos, libros y revistas especializadas y medios de comunicación.

Tabla № 4

Fuentes de información sexual reportadas por la muestra

\begin{tabular}{lcc}
\hline & $\mathrm{N}$ & $\%$ \\
\hline Familia & 544 & 55.5 \\
Amigos & 526 & 53.7 \\
Libros y revistas & 497 & 50.7 \\
\multicolumn{4}{r}{ Medios de comunicación masiva } \\
$\quad$ TV & 461 & 47.00 \\
$\quad$ Radio & 34 & 3.5 \\
Revistas & 117 & 11.95
\end{tabular}

Como puede observarse, la muestra reporta que su principal fuente de información fue la familia, seguida por los amigos y por literatura especializada. Entre los medios de comunicación, la televisión es reportada como la fuente de mayor frecuencia, seguida de lejos por las revistas.

Nos interesó asimismo averiguar qué porcentaje de la muestra afirmaba haber recibido educación sexual y, en especial, dónde la había recibido. El 89.2\% (874 personas) afirmó haber recibido alguna forma de educación sexual; sólo 95 personas (9.7\%) negaron haberla recibido.

La tabla $\mathrm{N}^{\circ} 5$ da a conocer los porcentajes de lugares en los que las personas afirman haber recibido educación sexual.
Tabla № 5

Lugares donde recibieron educación sexual

\begin{tabular}{lrr}
\hline LUGAR & $\mathrm{N}$ & \multicolumn{1}{c}{$\%$} \\
\hline Colegio & 770 & 78.6 \\
Universidad & 148 & 15.1 \\
Instituto & 10 & 1.0 \\
Otros & 140 & 14.3 \\
\hline
\end{tabular}

Como puede observarse el $78 \%$ de los encuestados reporta haber recibido educación sexual en el colegio en tanto que un $15 \%$ señala haberla recibido en la universidad.

Acerca del tiempo que duró el curso de educación sexual, el $45.8 \%$ de la muestra señaló que este curso duró hasta cinco horas, mientras que el $11.1 \%$ reportó que el curso duró entre seis y diez horas. Averiguando asimismo acerca del contenido de ese curso, el $60 \%$ de los encuestados reportó que dichos cursos incidieron en aspectos biológicos de la sexualidad; 39.8\% afirmó que se trataron los aspectos psicológicos, y el $36.2 \%$ destacó la presencia de aspectos sociales.

Otro aspecto de interés para nuestro trabajo fue averiguar algunas características demográficas de la muestra. Así, la pregunta número uno de esta parte de la encuesta indaga acerca de con quién vive el que responde. 742 personas $(75.7 \%)$ indicaron que vivían con sus padres; 18 personas $(1.8 \%)$ señalaron que lo hacían con su padre únicamente; 65 (6.6\%) indicaron que vivían con su madre, mientras que 92 personas $(9.4 \%)$ reportaron vivir con 
parientes. Sólo dos personas indicaron que vivían con su pareja.

Con respecto a las características de los padres el $40.8 \%$ de la muestra reportó que la madre tenía como ocupación su casa; $16.6 \%$ señaló que estaba jubilada y $15.3 \%$ que ejercía actualmente su profesión. Estos porcentajes varían de manera sustancial en lo que se refiere al padre, que fue reportado por $31.4 \%$ de la muestra como profesional y por $21.6 \%$ como jubilado.

La gran mayoría de los encuestados señaló que había sido educado por su padre y por su madre $(81.7 \%)$.

El nivel educativo de los padres fue, en el caso de la madre, predominantemente de secundaria completa (31.4\%) e instrucción superior completa (39.8\%); este último tipo de educación es asimismo el que predomina entre los padres $(59.2 \%)$.

Hemos obtenido también información acerca de algunas características subjetivas de la relación entre el encuestado y sus padres. El 2.3\% de los encuestados (23 personas) calificó de mala su relación con la mamá; $18.5 \%$ la calificaron de regular y $76.9 \%$ de buena. La mamá fue vista por lo general como poco $(35.2 \%)$ y regularmente (46.2\%) proclive al mal humor $\mathrm{y}$ al enojo. En el caso de los padres los porcentajes fueron $34 \%$ y $38.4 \%$, respectivamente.

Preguntados los encuestados acerca de con quién conversan cuando tienen un problema personal, se observó una predominancia en indicar a la figura materna: $14.9 \%$ de los encuestados señaló que siempre hablaban con su mamá frente al $6.9 \%$ que indicó que siempre hablaban con su papá. Es interesante anotar, como contraste, que $18.8 \%$ de los encuestados dijo que nunca conversaban sus problemas con su mamá; en el caso del papá este porcentaje se elevó a $36.8 \%$.

También en materia de sexualidad la madre parece ser el progenitor preferido para tratar estos asuntos: $61.5 \%$ de la muestra reportó haber hablado con su mamá contra $47.6 \%$ que indicó que lo hizo con el padre.

Con relación a la discusión del tema de las relaciones sexuales prematrimoniales, los encuestados afirman haber discutido con la madre muchas veces (17\%), y algunas veces $35.7 \%$. En el caso del padre, $7.2 \%$ de la muestra dijo haber discutido muchas veces este asunto con él, pero el $42.9 \%$ dijo que nunca lo había hecho.

Con relación a la discusión acerca del número de hijos que se quiere tener $20.1 \%$ de encuestados informó haberlo hecho con su madre; en tanto que sólo $8.4 \%$ con el padre. El uso de anticonceptivos fue asimismo discutido en gran medida con la madre: $45 \%$ de la muestra informa haberlo hecho algunas o muchas veces, mientras que el $29 \%$ de la muestra dice haberlo discutido con el padre.

El tema de la menstruación fue discutido sobre todo con la madre $(58 \%$ de 
la muestra dice haberlo hecho algunas o muchas veces, mientras que el $49 \%$ dijo que nunca lo discutió con su padre). Finalmente, cuándo tener el primer hijo fue discutido sobre todo con la madre (47\% optó por algunas o muchas veces) y no tanto con el padre (24\%).

\section{Aspectos de comportamiento sexual}

En esta sección se presentan los resultados acerca de conductas sexuales específicas de los estudiantes encuestados.

Con referencia a si en este momento salían con algún muchacho o muchacha, 518 personas (52.9\%) señalaron que en efecto salían con alguien, y $423(43.2 \%)$ indicaron que no. Estas salidas fueron reportadas como algo frecuente (más de un año) por 286 personas $(29.2 \%)$. Alrededor del $20 \%$ de la muestra reportó que estas salidas ocurrían en un período que iba desde menos de un mes hasta tres meses.

El 50.2\% de la muestra reportó haber estado muchas veces tomados de la mano de un muchacho o una muchacha; sólo el 8\% negó esto.

Con relación a la masturbación, 41.6\% negó tal práctica en los últimos doce meses; $28.7 \%$ la admitió con alguna frecuencia; $16.9 \%$ dijo que lo había hecho pocas veces; $y$, finalmente, el $7.4 \%$ dijo que lo había hecho muchas veces.

El 50\% de la muestra señaló haber dado o recibido un beso en la boca, pero $11.3 \%$ negó que esto hubiera ocurrido. Tocamientos de partes íntimas propias o de otros fueron negados por el $38.5 \%$ de la muestra, mientras que el $22 \%$ de ellas dijo que esto había ocurrido algunas veces y el $14.8 \%$ que esto ocurrió muchas veces.

El $46 \%$ de la muestra declaró haber tenido relaciones sexuales en los últimos doce meses (pocas, algunas o muchas veces); y con referencia a deseos sexuales el $80 \%$ de la muestra reportó en este mismo período (pocas, algunas y muchas veces) haberlos vivenciado.

El 53\% de la muestra refirió haber tenido relaciones sexuales; las edades reportadas como más frecuentes de la primera relación sexual fueron las que van entre 15 y 18 años. La primera relación sexual ocurrió en el $23 \%$ de los casos con el enamorado(a); en el $13.7 \%$ con alguna amistad y en el $11.3 \%$ con una prostituta, en el caso de los varones. La edad reportada de la primera pareja sexual estuvo en la mayoría de los casos entre los 16 y 20 años.

El $46 \%$ de la muestra señaló haber tenido más relaciones sexuales después de la primera, pero sólo el $26.2 \%$ dijo haberlo hecho con la misma persona. El 25.7\% afirma haber sido consciente de la posibilidad de un embarazo.

Pasemos ahora a un análisis un poco más detenido de los resultados presentados en la tabla $\mathrm{N}^{\circ} 6$. En primer lugar nos interesó establecer si es que existían diferencias entre el nivel de conocimiento sobre sexualidad y el sexo en 
los estudiantes de las universidades investigadas. Sobre un total de 21 ítems, los hombres obtuvieron un promedio de 14.54 y las mujeres 14.26; es decir, no se aprecia diferencias significativas, que sí se producen cuando se comparan los promedios por universidad: 14.61 en la universidad privada y 14.21 en la universidad estatal.

Efectivamente, el análisis de varianza de dos vías entre sexo y universidad con relación al nivel de conocimientos arrojó un $\mathrm{F}(1,979)=5.47, \mathrm{P}<.05$.

Esto revela que existe una tendencia en los estudiantes de la universidad privada a tener puntajes promedios más altos en conocimientos sobre sexualidad que los estudiantes de la universidad estatal.

Asimismo, podemos observar que aquellos que tuvieron relaciones sexuales presentan un mayor conocimiento sobre sexualidad que aquéllos que no las han tenido. Del mismo modo, aquellos que tuvieron relaciones sexuales y usan anticonceptivos, exhiben un mayor conocimiento sobre sexualidad que aquéllos que no hacen uso de anticonceptivos.

En lo que se refiere a asertividad encontramos que los estudiantes de la universidad privada tienen un mayor nivel que los de la universidad estatal. Asimismo, aquéllos que tienen relaciones sexuales y usan anticonceptivos tienen mayor nivel de asertividad que aquéllos que no usan anticonceptivos.
Respecto del control interno afectivo, los estudiantes de la universidad privada exhiben un mejor control que los de la universidad estatal, en tanto que aquéllos que no tienen relaciones sexuales exhiben también un mejor control que aquéllos que sí las tienen.

En la escala de toma de decisiones encontramos que, los estudiantes de la universidad privada tienen una mejor habilidad para tomar decisiones que los de la universidad estatal, cosa que ocurre de forma similar en las mujeres con respecto a los varones.

Con relación a la escala de obediencia, las únicas diferencias observadas se dan en las relaciones sexuales, donde aquéllos que no tienen relaciones sexuales exhiben un mayor apego a la obediencia que aquéllos que sí las tienen.

En la escala de autoestima sólo se pueden apreciar diferencias estadísticamente significativas en la variable sexo, notándose que las mujeres presentan un mayor nivel de autoestima que los varones, aunque en general la clasificación en base a las otras variables reflejan valores equivalentes.

En cuanto a organización, los estudiantes de la universidad privada presentan un mayor nivel que los de la universidad estatal, siendo esta diferencia significativa y más pronunciada en las mujeres que en los varones.

Con respecto a las conductas de riesgo se observa que las mujeres tienen una mayor tendencia a este tipo de con- 


\section{Fernández}

ductas que los varones. Del mismo modo, aquéllos que no tienen relaciones sexuales revelan una mayor tendencia a realizar conductas de riesgo que aquéllos que sí las tienen.

Finalmente, con respecto a la planificación encontramos que las mujeres revelan un mejor nivel que los varones.
Nos interesó a continuación determinar en qué medida todas las áreas antes evaluadas se vinculan entre sí. Para el efecto se determinaron coeficientes de correlación entre todas ellas y la edad.

Tabla № 6

Análisis comparativo de las variables estudiadas según universidad, sexo, relaciones sexuales y uso de anticonceptivos

\begin{tabular}{|c|c|c|c|c|c|c|c|c|}
\hline \multirow[t]{2}{*}{ Variables } & \multicolumn{2}{|c|}{ Universidad } & \multicolumn{2}{|c|}{ Sexo } & \multicolumn{2}{|c|}{$\begin{array}{c}\text { Relaciones } \\
\text { sexuales }\end{array}$} & \multicolumn{2}{|c|}{$\begin{array}{c}\text { Uso de } \\
\text { anticonceptivos }\end{array}$} \\
\hline & $\begin{array}{l}\text { Privada } \\
\mathrm{n}=491\end{array}$ & $\begin{array}{l}\text { Estatal } \\
\mathrm{N}=489\end{array}$ & $\begin{array}{l}\text { Masc. } \\
n=534\end{array}$ & $\begin{array}{l}\text { Fem. } \\
n=441\end{array}$ & $\begin{array}{l}S I \\
n=521\end{array}$ & $\begin{array}{l}\mathrm{NO} \\
\mathrm{n}=434\end{array}$ & $\begin{array}{l}S I \\
n=440\end{array}$ & $\begin{array}{l}\mathrm{NO} \\
\mathrm{n}=81\end{array}$ \\
\hline Conocimientos & 14.60 & $14.21^{*}$ & 14.53 & 14.26 & 14.89 & $13.86^{*}$ & 15.09 & $13.78^{*}$ \\
\hline Asertividad & 14.87 & $14.29^{\star}$ & 14.54 & 14.74 & 14.74 & 17.51 & 15.84 & $14.23^{*}$ \\
\hline $\begin{array}{l}\text { Control interno } \\
\text { afectivo }\end{array}$ & 17.31 & $16.58^{\star}$ & 16.90 & 17.00 & 16.76 & $17.16^{*}$ & 16.79 & 16.59 \\
\hline $\begin{array}{l}\text { Toma de } \\
\text { decisiones }\end{array}$ & 13.16 & $12.86^{\star}$ & 12.87 & $13.19^{\star}$ & 13.00 & 13.03 & 13.05 & 12.74 \\
\hline Obediencia & 11.14 & 11.09 & 11.12 & 11.10 & 10.91 & $11.35^{\star}$ & 10.87 & 11.06 \\
\hline Autoestima & 17.60 & 17.31 & 17.29 & $17.67^{*}$ & 17.49 & 17.41 & 17.51 & 17.43 \\
\hline Organización & 8.40 & $7.98^{*}$ & 8.06 & $8.36^{\star}$ & 8.20 & 8.18 & 8.26 & 7.89 \\
\hline Conducta de riesgo & 19.28 & 19.60 & 19.09 & $19.86^{\star}$ & 19.09 & $19.83^{*}$ & 19.10 & 18.91 \\
\hline Planificación & 24.23 & 23.80 & 23.51 & $24.64^{\star}$ & 23.91 & 24.14 & 24.03 & 23.32 \\
\hline
\end{tabular}

* $p<.05$.

Se han incluido los resultados de las comparaciones de las variables realizadas en los análisis de varianza de 3 vías. Los promedios en negrita indican la existencia de diferencias significativas. 
Las tablas que siguen presentan las correlaciones para la muestra total, sólo para el sexo femenino y sólo para el sexo masculino (véanse tablas $\mathrm{N}^{\mathrm{o}} 7$, 8 y 9$)$.
En primer lugar presentamos la tabla de correlación de todo el grupo. Como puede observarse, la variable autoestima y la variable organización son las que correlacionan significativamente

Tabla № 7

Coeficientes de correlación entre las diferentes variables investigadas en la muestra completa

\begin{tabular}{|c|c|c|c|c|c|c|c|c|}
\hline Edad & $\begin{array}{l}\text { Conoci- } \\
\text { miento }\end{array}$ & Asertividad & $\begin{array}{l}\text { Control } \\
\text { interno }\end{array}$ & Decisión & Obediencia & Autoestima & Organización & $\begin{array}{c}\text { Conducta } \\
\text { riesgosa }\end{array}$ \\
\hline Edad & $.17^{\star \star \star}$ & -.01 & $-.19^{\star * \star}$ & .01 & -.04 & .02 & $.09^{* *}$ & .06 \\
\hline Conocimiento & & $.12^{\star \star \star}$ & .05 & $.12^{\star \star \star}$ & $-.09^{\star \star}$ & $.11^{\star \star *}$ & .04 & .01 \\
\hline Asertividad & & & .06 & $.34^{* * *}$ & -.01 & $.22^{\star \star \star}$ & $.17^{\star \star \star}$ & .01 \\
\hline \multicolumn{9}{|l|}{ Control } \\
\hline interno afectivo & & & & $.09^{\star *}$ & .03 & $.08^{\star *}$ & .02 & -.05 \\
\hline Decisión & & & & & $.08^{*}$ & $.40^{\star \star *}$ & $.27^{\star \star \star}$ & $.09^{\star *}$ \\
\hline Obediencia & & & & & & $.07^{\star}$ & $.13^{\star \star \star}$ & $.20^{\star * *}$ \\
\hline Autoestima & & & & & & & $.28^{* * *}$ & -.03 \\
\hline Organización & & & & & & & & $.15^{\star \star \star}$ \\
\hline \multicolumn{9}{|l|}{ * $\quad p<.05$} \\
\hline \multicolumn{9}{|l|}{ ** $\quad p<.01$} \\
\hline \multicolumn{9}{|l|}{${ }^{* * *} p<.001$} \\
\hline $\mathrm{n}=980$ & & & & & & & & \\
\hline
\end{tabular}

Tabla № 8

Coeficiente de correlación entre las diferentes variables investigadas en el sexo masculino

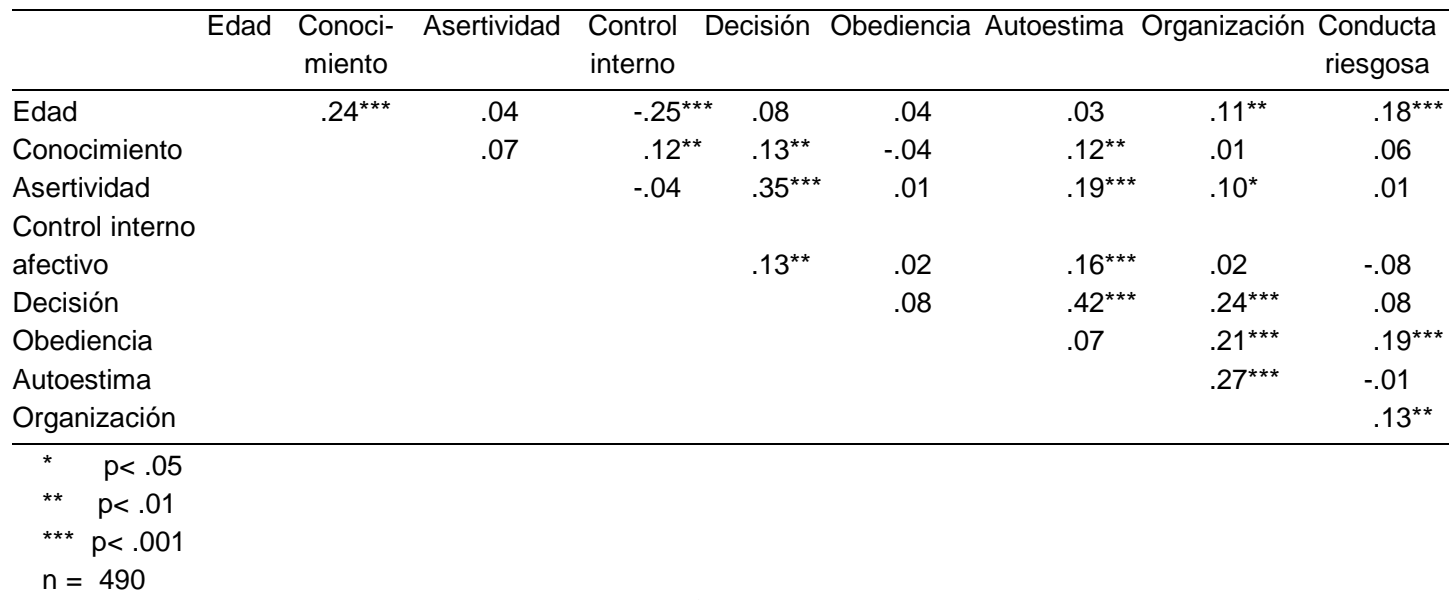


Fernández

Tabla № 9

Coeficiente de correlación entre las diferentes variables investigadas en el sexo femenino

\begin{tabular}{lcccccccc}
\hline & $\begin{array}{c}\text { Edad } \\
\text { Conoci- } \\
\text { miento }\end{array}$ & Asertividad & $\begin{array}{c}\text { Control } \\
\text { interno }\end{array}$ & Decisión & Obediencia Autoestima Organización Conducta \\
riesgosa
\end{tabular}

* $\quad p<.05$

** $\quad \mathrm{p}<.01$

*** $\quad p<.001$

$\mathrm{n}=441$

con las otras variables exploradas. Así, por ejemplo, autoestima correlaciona con toma de decisiones al .40; por su parte, organización correlaciona con autoestima y con toma de decisiones al .28 y .27 , respectivamente. Interesa en particular señalar que la conducta riesgosa en asuntos sexuales correlaciona en medida significativa, pero baja con decisión (.09), con organización (.11); $\mathrm{y}$, en especial, con obediencia (.20).

Con respecto a la edad observamos relaciones significativas en organización, conocimientos sobre sexualidad y control interno afectivo, expresando este último una tendencia negativa. Es interesante también la relación que se observa entre asertividad y toma de decisiones.

Desagregando la tabla por sexos, presentamos seguidamente las correlacio- nes entre los varones. Una vez más autoestima y organización son las variables que arrojan correlaciones más elevadas. En el caso de autoestima y decisión el coeficiente es de .42; organización por su parte correlaciona de manera significativa con toma de decisiones (.24), con autoestima (.27) y con obediencia (.21). Es interesante anotar la correlación negativa hallada entre control afectivo interno y edad (-.25). La variable edad guarda asimismo correlaciones significativas no sólo con control afectivo interno sino también con conocimiento (.24), con organización (.11) y con conductas riesgosas en materias sexuales (.18). Esta última variable presenta correlaciones significativas con obediencia y con organización (.19 y .13, respectivamente). 
Veamos a continuación las correlaciones en las mujeres. Lo primero que llama la atención es que la autoestima no guarda correlaciones tan altas con las otras variables, como lo sucedido en el caso de los hombres. En las personas del sexo femenino la autoestima correlaciona significativamente con toma de decisiones (.37) y con asertividad (.28); las correlaciones entre autoestima y conocimiento, aunque son significativas se mantienen en un coeficiente bajo (.10).

En lo que respecta a conductas riesgosas se encuentra en el sexo femenino que éstas correlacionan significativamente con obediencia (.22), y en un nivel mucho menor con toma de decisiones (.09).
Asimismo, es de interés destacar que la variable conocimiento presenta correlaciones significativas pero moderadas con asertividad (.19), con toma de decisiones (.12), con obediencia (la correlación es aquí negativa; -.14) y con autoestima (.10).

Como se puede notar, el análisis de las matrices de correlación tanto para varones como para mujeres, revelan patrones con tendencias similares a las observadas en la muestra completa, lo cual corrobora la consistencia de los resultados.

La tabla $\mathrm{N}^{\circ} 10$ agrupa los promedios de varones y mujeres que han tenido/no han tenido relaciones sexuales en cada una de las variables antes exploradas. Puede observarse que 218 varones y 61

Tabla № 10

Análisis comparativo de las variables por sexo y relaciones sexuales según universidad

\begin{tabular}{|c|c|c|c|c|c|c|c|c|}
\hline & \multicolumn{4}{|c|}{ Universidad privada } & \multicolumn{4}{|c|}{ Universidad estatal } \\
\hline & $\begin{array}{l}\text { Varones } \\
\text { con } \\
\text { rel. sex. }\end{array}$ & $\begin{array}{l}\text { Varones } \\
\text { sin } \\
\text { rel. sex. }\end{array}$ & $\begin{array}{l}\text { Mujeres } \\
\text { con } \\
\text { rel. sex. }\end{array}$ & $\begin{array}{l}\text { Mujeres } \\
\text { sin } \\
\text { rel. sex. }\end{array}$ & $\begin{array}{l}\text { Varones } \\
\text { con } \\
\text { rel. sex. }\end{array}$ & $\begin{array}{l}\text { Varones } \\
\text { sin } \\
\text { rel. sex. }\end{array}$ & $\begin{array}{l}\text { Mujeres } \\
\text { con } \\
\text { rel. sex. }\end{array}$ & $\begin{array}{l}\text { Mujeres } \\
\quad \text { sin } \\
\text { rel. sex. }\end{array}$ \\
\hline$N=$ & 218 & 59 & 61 & 153 & 189 & 73 & 53 & 144 \\
\hline Conocimiento & & & & & & & & \\
\hline sobre sexualidad & $15.06^{*}$ & 13.70 & $15.67^{*}$ & 13.87 & 14.40 & 13.89 & $15.03^{*}$ & 13.84 \\
\hline Asertividad & 14.83 & 14.68 & 15.39 & 14.81 & 14.42 & 13.72 & 14.73 & 14.47 \\
\hline Control & & & & & & & & \\
\hline $\begin{array}{l}\text { interno afectivo } \\
\text { Toma de }\end{array}$ & 17.39 & 17.53 & 16.70 & 17.37 & 16.18 & 16.93 & 16.28 & 17.06 \\
\hline decisiones & 12.96 & 13.11 & 13.72 & 13.25 & 12.85 & 12.39 & 12.73 & 13.08 \\
\hline Obediencia & 11.12 & 10.98 & 10.24 & $11.51^{*}$ & 11.02 & 11.24 & 10.35 & 11.27 \\
\hline Autoestima & 17.39 & 17.64 & 18.08 & 17.77 & 17.30 & 16.53 & 17.84 & 17.43 \\
\hline Organización & 8.02 & 8.20 & 9.06 & 8.69 & $8.21^{*}$ & 7.40 & 7.67 & 8.07 \\
\hline Conducta riesgosa & 18.56 & 19.35 & 20.14 & 19.89 & 19.37 & 19.66 & 19.03 & 20.09 \\
\hline Planificación & 23.67 & 23.81 & 25.44 & 24.72 & $23.64^{*}$ & 22.24 & 23.96 & 24.53 \\
\hline $\begin{array}{ll}* & p<.05 \\
\star * & p<.01 \\
\star \star * & p<.001\end{array}$ & & & & & & & & \\
\hline
\end{tabular}


mujeres de la universidad privada reportan haber tenido relaciones sexuales; los que dicen no haberlas tenido son 59 varones y 153 mujeres. En el caso de la universidad estatal, 189 varones y 53 mujeres afirmaron haber tenido relaciones sexuales mientras que 73 varones y 174 mujeres dijeron que no las habían tenido.

Encontramos que en general las personas que afirman haber tenido relaciones sexuales presentan un promedio de conocimiento sexual mayor que el de las personas que afirman no haberlas tenido. En el caso de varones y mujeres de la universidad privada y en el de las mujeres de la universidad estatal las diferencias son significativas. Aunque en asertividad las personas con experiencia sexual puntúan igualmente más alto en los dos sexos, no se registran diferencias significativas entre las dos universidades. Es digno de anotarse que en el caso de control interno afectivo la tendencia es a la inversa; es decir, quienes no han tenido relaciones sexuales puntúan más alto y esto ocurre siempre en el caso de las mujeres que se muestran como las más controladas.

Igualmente, en toma de decisiones observamos una tendencia más variada aunque no se aprecian diferencias significativas.

En la variable obediencia encontramos hechos que apuntan a diferentes tendencias: los alumnos varones de la universidad privada que han tenido relaciones sexuales puntúan más alto que los que no las han tenido; los varones de la universidad estatal que no se han iniciado sexualmente puntúan aún más alto que los que ya tuvieron experiencias sexuales. Las mujeres sin experiencias sexuales de ambas universidades presentan promedios más elevados que las que han tenido experiencias sexuales, notándose que las diferencias significativas se presentan sólo en las mujeres de la universidad privada.

En autoestima se observa, en el caso de los varones de la universidad privada que no han tenido relaciones sexuales, un promedio mayor pero no significativo con respecto a los que sí han tenido; en las mujeres la tendencia es a la inversa. En general se observa un promedio mayor en autoestima en la muestra de la universidad privada cuando se la compara con la universidad estatal, aunque no existen diferencias estadísticamente significativas.

En organización destaca el hecho de que los varones de la universidad estatal que han tenido relaciones sexuales puntúan más alto que los que no las han tenido. En la conducta de riesgo es interesante anotar que las personas que tienen el más alto puntaje en la universidad estatal son las mujeres que no han tenido relaciones sexuales, mientras que en la universidad privada lo son las mujeres que sí han tenido relaciones sexuales, no apreciándose la existencia de diferencias estadísticamente significativas. 
Tabla № 11

Análisis de regresión logística para las relaciones sexuales

\begin{tabular}{lrrr}
\hline Variable & B & S.E. & \multicolumn{1}{c}{ Wald } \\
\hline Universidad(1) & -.3798 & .1602 & $5.6181^{* * *}$ \\
Edad & -.2544 & .0336 & $57.1999^{* * *}$ \\
Sexo(1) & -2.0789 & .1753 & $140.5997^{* * *}$ \\
Conocimiento & -.1343 & .0311 & $18.6434^{* * *}$ \\
Obediencia & .1308 & .0404 & $10.4770^{* * *}$ \\
Conv. madre & .0480 & .0199 & $5.8349^{* * *}$ \\
Constante & 6.3464 & .9379 & $45.7876^{* * *}$ \\
\hline
\end{tabular}

\begin{tabular}{lc}
-2 Log Likelihood $=$ & 961.19 \\
Goodness of Fit $=$ & 1042.54 \\
Cox \& Snell-R^2 $=$ & .33 \\
Nagelkerke- $R^{\wedge} 2=$ & .44 \\
Chi-Cuadrado del & \\
modelo $\quad=$ & $390.46^{* *}$ \\
\hline$* \quad \mathrm{p}<.05$ & \\
$* * \quad \mathrm{p}<.01$ & \\
$* * * \quad \mathrm{p}<.001$ & \\
$\mathrm{~N}=980$ \\
Sistema de codificación : \\
Sexo: masculino (1), femenino (0) \\
Universidad: privada (1), estatal $(0)$
\end{tabular}

Con la finalidad de poder determinar qué variables permiten predecir quiénes tienen relaciones sexuales y quiénes no las tienen, se utilizó el análisis de regresión logística que permite trabajar con variables cuantitativas, como es el caso de la edad, el nivel de conocimientos sobre sexualidad, el nivel de obediencia, así como con variables cualitativas, como conversar con la madre, la universidad de procedencia y el sexo, las cuales fueron transformadas en variables DUMMY (1.0).

Los resultados, como puede observarse en la tabla $\mathrm{N}^{\circ} 11$, demostraron que todas las variables se adecúan al modelo (Chi: cuadrado $=390.46, \mathrm{p}<$ .001 ), encontrándose que la variable con mayor ponderación es pertenecer al sexo masculino, seguido por estudiar en la universidad privada, la edad, el nivel de conocimiento sobre sexualidad, obediencia y conversar con la madre.

Tabla № 12

Clasificación de la predicción de los resultados de la regresión logística de los que tuvieron relaciones sexuales con punto de corte de $\mathbf{0 . 5 0}$

\begin{tabular}{lccc}
\hline $\begin{array}{l}\text { Valor } \\
\text { observado }\end{array}$ & \multicolumn{3}{l}{ Valor de predicción } \\
\hline & Sí & No & $\%$ \\
\hline Sí & 412 & 109 & 79.08 \\
No & 117 & 340 & 74.04 \\
\hline Total & 529 & 449 & 76.89 \\
\hline
\end{tabular}

El análisis de la eficiencia de la regresión que se exhibe en la tabla $\mathrm{N}^{\circ} 12$ indica que existe un $76.89 \%$ de capacidad para distinguir los que tienen de los que no tienen relaciones sexuales. 
Tabla № 13

Sumario del análisis de regresión logística para el uso de anticonceptivos en aquéllos que tienen relaciones sexuales

\begin{tabular}{lrrr}
\hline Variable & B & S.E. & \multicolumn{1}{c}{ Wald } \\
\hline Conocim. & -.1783 & .0464 & $14.7726^{* * *}$ \\
Universi. (1) & -.7434 & .2561 & $8.4243^{* * *}$ \\
Constante & 1.2364 & .6650 & $3.4564^{* * *}$ \\
\hline
\end{tabular}

\begin{tabular}{l}
-2 Log Likelihood \\
Goodness of Fit \\
Cox \& Snell $-\mathrm{R}^{\wedge} 2$ \\
Nagelkerke $-\mathrm{R}^{\wedge} 2$ \\
Chi-Cuadrado de \\
Modelo \\
\hline$* \quad \mathrm{p}<.05$ \\
${ }^{* *} \quad \mathrm{p}<.01$ \\
${ }_{* * *} \quad \mathrm{p}<.001$ \\
$\mathrm{n} \quad=521$
\end{tabular}

Sistema de codificación:

Universidad: privada (1), estatal (0)

Tabla № 14

Clasificación de la predicción de los resultados de la regresión logística de los que usan anticonceptivos con valor de corte de $\mathbf{0 . 5 0}$

\begin{tabular}{lccc}
\hline $\begin{array}{l}\text { Valor } \\
\text { observado }\end{array}$ & \multicolumn{3}{l}{ Valor de predicción } \\
\hline Sí & No & $\%$ \\
\hline Sí & 438 & 2 & 99.55 \\
No & 78 & 3 & 3.70 \\
\hline Total & 516 & 5 & 84.64 \\
\hline
\end{tabular}

Posteriormente, con la finalidad de establecer las variables que permitan predecir el uso de anticonceptivos en aquéllos que mantienen relaciones sexuales, se incluyeron en la regresión logística el nivel de conocimiento sobre sexualidad y universidad de procedencia (véase tabla $\mathrm{N}^{\circ} 13$ ). Los resultados corroboraron la adecuación del modelo (Chi cuadrado $=26.89$. $\mathrm{p}<$ .001). Se encontró que la mayor ponderación corresponde a pertenecer a la universidad privada, seguido del nivel de conocimientos sobre sexualidad. El análisis de eficiencia revela una capacidad del $86.64 \%$ de acierto para establecer si utilizan o no anticonceptivos (véase tabla $\mathrm{N}^{\mathrm{o}} 14$ ).

El gráfico de la interacción por edad y sexo de la escala de obediencia presenta los resultados del ANOVA de dos vías de los factores que se han realizado para estudiarla. Estas observaciones indican que la variable edad y la variable sexo de forma independiente no establecen diferencias significativas, pero el análisis de la interacción alcanza una $\mathrm{F}=5.65$ que tiene asociado un nivel de significatividad al 0.004, lo cual determina la existencia de la interacción (véase gráfico $\mathrm{N}^{\circ} 1$ ).

En el gráfico se observa que las mujeres obtienen el mayor nivel de obediencia entre los 16 y 20 años en tanto que su menor nivel lo expresan entre los 26 y 30 años. Por el contrario los varones alcanzan su menor nivel de obediencia entre los 16 y 20 años en 
Gráfico № 1

Interacción por edad y sexo de la escala de obediencia

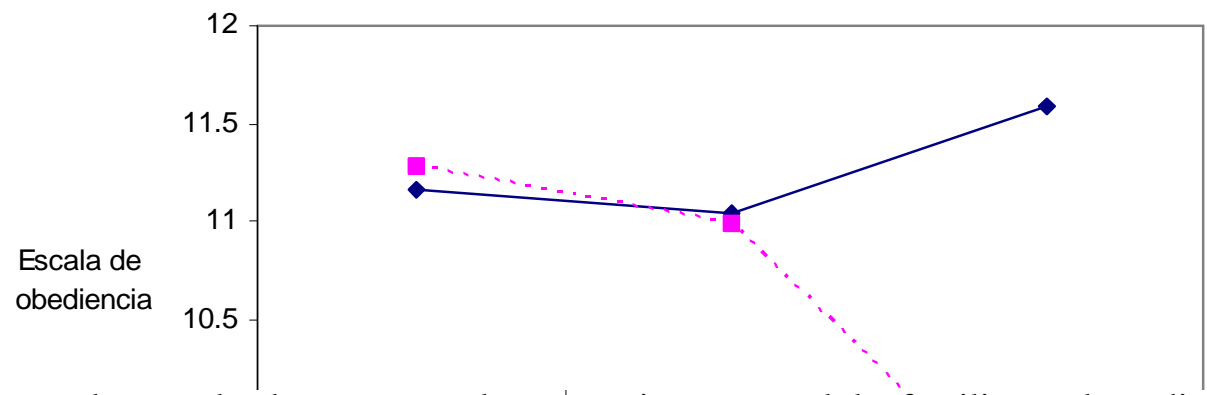

tanto que el mayor lo alcanzan entre los 26 y 30 años.

\section{DiscUSIÓN}

La investigación realizada comprende, como puede verse, numerosas variables exploradas tanto en hombres como en mujeres. El número de variables que hemos explorado hace justicia a la complejidad inherente a la conducta sexual y a las actitudes con referencia a la sexualidad. Desde los trabajos de Eysenck, el conocido psicólogo inglés, se cuenta con una base de información relativamente sólida que permite sostener la vinculación estrecha entre conducta, actitudes sexuales y personalidad (Eysenck, 1971, 1978; Eysenck \& Wilson, 1979).

La discusión se referirá a este punto y también a información que podríamos llamar aspectos sociológicos y antropológicos de la sexualidad.

Un primer hallazgo que queremos destacar es que en materia de conoci- miento sexual la familia y el medio ambiente compiten como la principal fuente de información. En efecto, tal como se puede ver en la tabla $\mathrm{N}^{\circ} 4$, los porcentajes de sujetos que señalan que la familia es su principal fuente de información son semejantes a los de los amigos, las revistas y los medios de comunicación masivos.

Esto puede verse desde dos ángulos. En primer lugar, puede destacarse este hecho como algo positivo si se tiene en cuenta que todo lo referido a sexualidad fue por mucho tiempo en el Perú un tema tabú en la esfera familiar (Fuller, 1993, 1997). El porcentaje relativamente elevado de las personas que dicen que su familia es su principal fuente de información podría, por tanto, ser entendido como un signo de apertura de la sociedad peruana hacia la discusión abierta de los temas sexuales. No sólo esto; como lo señala La Rosa (1997) "las relaciones familiares armónicas, desarrolladas en un clima 
de confianza y estabilidad, aún cuando se vivan las condiciones de pobreza, constituyen un factor de protección y de retraso de la relación sexual" (p. 116). Téngase en cuenta, además, que por lo menos uno de los progenitores de muchas de las familias de las cuales proviene nuestra muestra, tiene un nivel de instrucción superior, lo que por lo general se vincula con actitudes más democráticas y menos conservadoras. En un trabajo llevado a cabo hace algunos años, Alegría Majluf (1988) destacó comportamientos y actitudes más democráticas en la clase media, cuando se compara ésta con niveles socioeconómicos menos favorecidos.

Pero también se puede entender estos porcentajes como indicadores de la importancia que tienen los agentes extrafamiliares en la adquisición de conocimientos sobre sexualidad. Obsérvese que el $44 \%$ de la muestra indicó que no había recibido ningún tipo de información sexual en la familia.

Este último punto de vista, el de la importancia de los agentes extrafamiliares, se ve reforzado por el hecho de que casi el $90 \%$ de encuestados afirmó haber recibido alguna forma de información sexual, identificando al colegio como el lugar en el que la recibió. Si bien estos porcentajes pueden ser entendidos como indicadores de actitudes más abiertas hacia la sexualidad, es necesario verlos a contraluz de su contenido. El $60 \%$ de los encuestados señaló que la información fue fundamentalmente de corte biológico, y sólo $40 \%$ indicó que se había tratado aspectos de corte psicológico.

En un sentido más bien negativo, podríamos afirmar que se instruye, se ofrece datos en materia de sexualidad, pero no se incide en la esfera afectiva ni valorativa, centrada en la persona (Fernández, 1989). Esta información se vuelve aún más negativa si se considera que más o menos la mitad de los encuestados afirma no haber recibido información alguna en casa. Esto quiere decir que la información es adquirida de modo casual o por fuentes como amigos o noticias periodísticas, información que será elaborada por cada quien sin tener la posibilidad de discutir esto con sus familiares y recibir el influjo de la atmósfera familiar que, como lo ha señalado La Rosa (1997), parece proteger a los adolescentes y jóvenes de relaciones sexuales casuales y por lo tanto riesgosas.

Sigamos con la familia. La madre aparece como el interlocutor preferido para tratar temas sexuales. Puede inferirse que ella es la primera fuente de consulta, ya no sólo en materia de sexualidad sino, en general, en toda suerte de problemas; algo que encaja bien en líneas generales con el carácter matricéntrico de la sociedad peruana (Fu1ler, 1993; Callirgos, 1997). En general, puede afirmarse que la imagen de la madre que predomina en nuestra muestra es positiva: $76.9 \%$ de los en- 
cuestados calificó su relación con la madre de buena.

No hemos averiguado qué tipo de valores representaban las madres de los integrantes de nuestra muestra, pero es posible suponer que sus valores son de carácter más bien conservador, lo que parece prevenir relaciones sexuales no buscadas.

Sin embargo, poco más de la mitad de la muestra reporta haber tenido relaciones sexuales, observándose la tendencia a iniciarse sexualmente vinculando el sexo con el afecto (recuérdese que el $23 \%$ de los casos reporta la primera relación sexual con el enamorado), pues sólo un $11 \%$ de personas (todas evidentemente de sexo masculino) dicen haberse iniciado sexualmente con prostitutas. Este hallazgo corrobora el efectuado por Valdez y colaboradores, quienes asímismo encontraron una mayor frecuencia de iniciación sexual con enamorados y amigos (Valdez et al., 1998). Nuestros resultados confirman por tanto la tendencia a una relación sexual inicial como resultado de vínculos afectivos o de atracción física, a diferencia de lo que ocurría en el pasado, cuando la iniciación sexual de los varones ocurría en prostíbulos (Ponce \& La Rosa, 1995).

Otro hallazgo que reviste importancia lo constituyen las correlaciones de la autoestima con las diferentes variables que hemos explorado. Varios trabajos previos en la literatura internacional reportan la existencia de vínculos estrechos entre autoestima y conducta sexual (e.g. Walsh, 1991). En el presente trabajo encontramos que a nivel de todo el grupo la autoestima guarda importantes correlaciones con algunas de las variables exploradas, en particular, como era de esperarse con asertividad y con toma de decisiones.

Sin embargo, las correlaciones entre autoestima y conducta riesgosa en materia sexual no son dignas de ser tomadas en cuenta. Esto se repite tanto en un sexo como en el otro. Como era de esperar, la variable edad correlaciona de modo significativo con el control afectivo interno y la capacidad de organización. Es de interés destacar que en las personas de sexo femenino hay una correlación negativa entre edad y obediencia, lo que significa que a mayor edad menor obediencia.

En general, las correlaciones ofrecen una panorámica que abarca los complejos vínculos que se dan entre diferentes variables de la personalidad, y que, a no dudarlo, ejercen su influencia también en el plano de las actitudes y en el más concreto de las conductas sexuales.

Tal vez la información de mayor significado provenga, sin embargo, de las comparaciones intersexo, tomando en cuenta las universidades y la presencia/ausencia de relaciones sexuales.

Haber tenido relaciones sexuales guarda relación con el nivel de conocimiento sobre sexualidad, como lo demuestra el puntaje más elevado alcan- 
zado por quienes las tuvieron, algo que también encontró La Rosa (1997). Esto puede entenderse como que las personas que han tenido relaciones sexuales consideran que la experiencia de haberlas tenido ha aumentado de manera sustancial su nivel de información. Se verían ellas mismas como personas "más experimentadas" en el plano sexual.

Pasemos ahora a referirnos a las relaciones entre asertividad/obediencia y conducta sexual. Es interesante observar que la variable obediencia parece ser de gran importancia en la presencia/ausencia de relaciones sexuales. Tanto en hombres como en mujeres, así como en una y en otra universidad, se observa que el puntaje más alto en obediencia lo tienen las mujeres que no han tenido relaciones sexuales. Independientemente de si han tenido o no relaciones sexuales, son las mujeres las que puntúan más alto en obediencia. Explicable esto en una sociedad como la peruana en la cual las actitudes machistas siguen siendo muy frecuentes y en la que, además, en los procesos de socialización que ocurren en la familia, se sigue enfatizando todavía la sumisión y el respeto a las normas conservadoras en las conductas de las mujeres (Ponce y La Rosa, 1995; Fuller, 1993).

Esta tendencia al respeto de los valores conservadores adquiere su máxima expresión en el caso de las mujeres sin relaciones sexuales: las diferencias de ellas con las que sí han tenido relaciones sexuales son estadísticamente significativas. Esto puede ser entendido como que las que han tenido relaciones sexuales tienden a mirar las normas familiares y sociales con un poco más de distancia crítica, relativizándolas en el contexto de sus propias existencias. Este hallazgo vale tanto para personas de una universidad como de la otra.

Pero, además, puede observarse que la asertividad guarda relación con mujeres que expresan un cierto conocimiento sexual. La capacidad para autoafirmarse parece vincularse con una mayor búsqueda de conocimiento en materia de sexualidad. La mayor autonomía e independencia de criterio que supone la asertividad se expresaría también en un mayor deseo de informarse en el terreno sexual.

De singular interés es el examen de la variable conducta de riesgo. Aquí se produce un hecho paradójico: las mujeres con relaciones sexuales en la universidad privada puntúan más alto que las que no las tuvieron, pero la tendencia es opuesta y estadísticamente significativa en la universidad estatal, en la que son las mujeres sin relaciones sexuales las que puntúan más alto.

Siendo la universidad privada una casa de estudios que tiene estudiantes de clase media y alta, puede suponerse que en ellos -como en la clase media instruida en general- hay una actitud más abierta hacia el sexo, que se expre- 
sa en un mayor nivel de conocimiento sexual, y que asimismo puede, en ciertos casos, expresarse en experiencias sexuales prematrimoniales. Por otro lado, recuérdese que en materia de conocimiento sexual no hay mayores diferencias entre hombres y mujeres.

En el caso de la universidad estatal, la situación indicaría lo contrario; integrada por estudiantes de menor nivel socioeconómico, la muestra femenina arroja menor nivel de conocimiento sexual y eso, tal vez, la lleva involuntariamente a situaciones que pueden suponer más riesgos.

Los resultados de nuestro trabajo ponen de manifiesto, creemos, las complejas vinculaciones entre la conducta sexual y algunos rasgos de personalidad.

Estas vinculaciones son complejas y recién comienzan a ser reconocidas. No cabe duda de que Hans Jürgen Eysenck tuvo gran mérito en esto, con su sofisticada teoría de la personalidad. Como todo rasgo de personalidad, los explorados acá son influidos por el contexto cultural en el cual vive la persona.

El medio peruano ofrece perfiles contrastantes. Por un lado, una minoría instruida y con valores modernos; por el otro lado, una gran mayoría de limitados recursos económicos y que por lo general se distingue por valores conservadores, uno de ellos el machismo, realidad psicosocial que atraviesa todos los estratos de la sociedad peruana.
El trabajo con muestras de dos universidades, una estatal a la que concurren estudiantes de los llamados estratos $\mathrm{B}, \mathrm{C}$ y D; y otra privada, con estudiantes de los estratos A y B, permite verificar de qué modo las vinculaciones entre rasgos de personalidad y conductas sexuales se manifiestan en diferentes niveles de la sociedad.

Un rasgo conservador de la sociedad peruana es la insistencia en la obediencia, que puede ser definida como un respeto excesivo y por lo general poco crítico de normas sociales y figuras de autoridad.

La obediencia aparece en nuestro trabajo como una variable crucial en el terreno sexual. Altos puntajes en obediencia están asociados a no-iniciación sexual, mientras que la asertividad en el caso de las mujeres se vinculó con mayor conocimiento sexual.

La relación inversa encontrada entre edad y obediencia (véase gráfico $\mathrm{N}^{\circ} 1$ ) podría significar que el varón joven es menos apegado a las reglas y normas sociales y, de alguna manera, rebelde, en tanto que cuando llega a la madurez, su apego a las normas sociales se incrementa significativamente, tal vez por las exigencias que le demanda la sociedad en esta etapa evolutiva.

Por el contrario, las mujeres jóvenes se muestran más cercanas a las normas sociales y las respetan, fundamentalmente porque los condicionamientos sociales así lo establecen y ésa es la conducta que se espera de ellas, en 
tanto que a medida que maduran tienden a ser más autónomas.

Una conclusión provisional es que actitudes conservadoras y de adecuado respeto a las figuras de autoridad parecen ser buenos "protectores" contra conductas sexuales precoces y por ende riesgosas. De ser cierto esto, se devolvería nuevamente a los padres la responsabilidad de establecer valores apropiados en el terreno sexual. Es decir, una adecuada formación de la personalidad (autoestima sana y sólida, asertividad adecuada, toma de decisiones planificada y apropiado sentido de organización) sería la mejor garantía de conductas sexuales poco riesgosas.

Esta conclusión nos parece de interés porque relativiza la influencia que se suele atribuir a los programas de educación sexual que se imparten en los colegios. Resulta explicable el que esto suceda, puesto que hasta no hace mucho el silencio, la evasión y la ausencia de diálogo eran lo habitual en las familias al momento de tratar el tema del sexo con los hijos. Como podemos darnos cuenta, esto ha cambiado mucho y, al menos de acuerdo con los resultados que hemos obtenido, los muchachos suelen hoy día tratar con más apertura el tema del sexo con sus padres que lo que sucedía, por ejemplo, hace una generación.

¿Significa esto que los programas de educación sexual implementados por el Estado carecen de valor? En modo alguno se puede afirmar esto. Como ya vimos, estos programas insisten sobre todo en los aspectos biológicos de la sexualidad, algo que por lo general no es conocido por los padres. La ecuación de regresión logística presentada en la tabla $\mathrm{N}^{\circ} 13$ nos permite afirmar que en el uso de anticonceptivos, la figura materna no juega ningún papel (cosa que sí sucede al momento de tratar los temas sexuales en general). Este último tema es de incumbencia de los programas de educación sexual.

La cantidad de información obtenida en el presente estudio no ha podido ser tratada en detalle debido a las limitaciones de espacio propias de todo artículo.

Señalemos sólo que análisis más detenidos, que tomen en cuenta variables más precisas, como por ejemplo el nivel socioeconómico del distrito de residencia; o atributos de los padres (buen humor/mal humor; calidad de la relación entre ellos y con los hijos, etc.), arrojarán nueva información de gran valor acerca de la influencia de los condicionamientos sociales en las conductas sexuales de los adolescentes y jóvenes peruanos, en las vísperas mismas del fin del milenio. Es propósito nuestro llevar a cabo estos análisis y darlos a conocer en futuras publicaciones.

Consideramos que esta más amplia información permitirá una aproximación más objetiva, más realista, de las conductas en estudio, de modo que sirva de base para el desarrollo de pro- 
gramas de intervención más integrales y de mayor efectividad.

\section{REFERENCIAS}

Acosta, S. \& Bernal M. (1988). Actividad sexual y métodos anticonceptivos utilizados por los estudiantes de la Universidad Nacional de Colombia. Bogotá.

Cáceres, C.F., Rosasco, A.M., Muñoz, S., Gotuzzo, E., Mandel, J.R. \& Hearst, N. (1992). Necesidades educativas en relación con la sexualidad humana y el sida entre estudiantes y profesores de escuelas secundaria de Lima. Revista Latinoamericana de Psicología, 24, 109-123.

Callirgos, J. C. (1997). Sobre héroes y batallas. Lima: Demus.

Cochran, S.D. \& Peplan, L.A. (1991). Sexual risk reduction behaviors among young heterosexual adults. Soc. Sci. Med., 33, 25-36.

Dewill, Ph. (1994). Now for the truth about Americans and sex. Time International, Vol. 42, 44-50.

Chaparro, N., Pedraza, M., Rodríguez, M. \& Rodríguez, A. (1987). Conocimientos sobre sexualidad humana impartidos a las estudiantes de la Fundación Escuela de Ciencias de la Salud, Facultad de Enfermería. Hospital San José. Bogotá.

Díaz-Guerrero, R. (1975). El diferencial semántico del idioma español. México DF: Trillas.

Eysenck, H.J. (1971). Personality and sexual adjustment. British Journal of
Psychiatry, 118, 593-608.

Eysenck, H.J. (1978). Sex and personality. Londres: Abacus.

Eysenck, H.J. \& Wilson, G.D. (1979). The psychology of sex. Londres: New English Library/Times Mirror.

Fernández, M. (1989). Conocimientos y actitudes sexuales de escolares adolescentes. Evaluación y lineamientos para un programa de educación sexual. Lima: Universidad de Lima.

Ferrando, D., Sigh, S. \& Wulf, D. (1989). Adolescentes de hoy y padres de mañana: Perú. New York: The Alan Gutmacher Institute.

Ferrater Mora, J. \& Cohn, P. (1981). Ética aplicada. Del aborto a la violencia. Madrid: Alianza Universidad.

Franco, J.A., (1992). Insuficiente educación sexual en medicina. Acta Psiquiátrica y Psicológica de América Latina, 38, (2). Buenos Aires.

Fuller, N. (1993). Dilemas de la femineidad. Mujeres de clase media en el Perú. Lima: Pontificia Universidad Católica del Perú.

Fuller, N. (1997). Identidades masculinas. Lima: Pontificia Universidad Católica del Perú.

Giraldo, O. (1989). Explorando las sexualidades humanas. Aspectos psicosociales. México DF: Trillas.

Kinsey, A.C.; Pomesoy, W.B. \& Martín, C. E. (1948). Sexual behavior in the human male. Philadelphia: Saunders.

Kinsey, A.C.; Pomesoy, W.B.; Martín, C. E. \& Gebhard, P. H. (1953). Sexual behavior in the human female. Philadelphia: Saunders. 
La Rosa, L. (1997). Adolescencia e iniciación sexual. Lima: Universidad Peruana Cayetano Heredia.

León, R. \& Cossío de Preciado, A. M. (1993). Actitudes y comportamiento sexuales en un grupo de estudiantes universitarios de Lima Metropolitana. Revista de Neuro-psiquiatría, 56, 33-58.

McCary, J. L. \& McCary, St. (1990). Sexualidad humana. México, D. F.: El Manual Moderno.

Majluf, A. (1989). Prácticas de crianza en madres de estratos socioeconómicos medio y bajo de Lima. Revista de Psicología, 7, 151-161.

Milgram, S. (1974). Obedience to authority. Nueva York: Harper and Row.

Pérez de Gabaldón, M. (1986). Estudio comparativo en estudiantes universitarios sobre información sexual básica: análisis general. Acta Científica, 37 (3), 327-331.

Pick, S. \& Andrade, P. (1991). Bases para el desarrollo y evaluación de programas de educación sexual para adolescentes. Memoria de la Conferencia Internacional sobre Fecundidad en Adolescentes en América Latina y el Caribe. Oaxaca, México.

Pick, S.; Díaz Loving, R. \& Andrade, P.; (1988). Adolescentes en la ciudad de México: estudio psicosocial de las prácticas anticonceptivas y el embarazo no deseado. Informe presentado a la Organización Mundial de la Salud y el Fondo de Población de Naciones Unidas, Washington DC.

Ponce, A. \& La Rosa, L. (1995). Nuestra sexualidad. Mis abuelos, mis padres y yo. Construcciones sociales de la sexualidad en tres grupos genera- cionales. Lima: Pontificia Universidad Católica del Perú.

Rodríguez Marín, J. (1995). Psicología social de la salud. Madrid: Síntesis.

Schofield, M. (1977). El comportamiento sexual de los adultos (18 a 25 años). Barcelona: Fontanella.

Sevillano, M. (1986). Sexualidad en los estudiantes de la Universidad Nacional San Luis Gonzaga de Ica. IV Congreso Nacional de Psicología, Perú.

Silva, P., Alvarado, R., Palavecino, L., Sandoval, L., Quevedo, F., Girardi, G., Aranda, W. (1988). Conocimientos sobre sexualidad en estudiantes universitarios. Cuadernos Médicos Soc., 29 (1), 11-16, Santiago de Chile.

Soto Cáceres, V. (1972). Comportamiento sexual del universitario peruano. Quince años de investigación científica. Lima: Concytec.

Valdez, H.; Adachi, R. \& Gotuzzo, E. (1991). Prácticas sexuales en la población universitaria de Lima: análisis de los factores de riesgo para la transmisión sexual del virus inmunodeficiencia. Revista Médica Herediana, 2, 1823.

Walsh, A. (1991). Selfesteem and sexual behavior: Exploring gender differences. Sex Roles, 25, 441-450.

Zuckerman, M.; Buchsbaun, M. \& Murphy, D. (1980). Sensation-seeking and its biological correlates. Psychological Bulletin, 88, 187-214. 


\section{APÉndice 1}

\section{DEFINICIÓN DE LAS ÁREAS AFECTIVAS}

\section{Asertividad}

Rasgo de personalidad consistente en conductas unívocas destinadas a hacer valer los derechos propios y a expresar con decisión sentimientos de agrado y desagrado, en la relación con otras personas.

Las conductas asertivas se ajustan a las normas sociales habituales y toman en consideración los sentimientos de los otros, pero expresan de modo claro los puntos de vista de la persona.

\section{Control interno afectivo}

Conjunto de actitudes y conductas de una persona que la llevan a suponer y a sentir que ella tiene un adecuado control de sus sentimientos, emociones y estados de ánimo, y que posee un nivel apropiado de autonomía, lo que le permite establecer vínculos con los demás en un plano de igualdad y a evitar reacciones emocionales desmedidas o que se alejan de las normas sociales.

\section{Toma de decisiones}

Conjunto de actitudes y conductas que hacen que el individuo se sienta autónomo y responsable por sus actos, de modo tal que la persona siente que ella puede regular su comportamiento, optando por patrones de actuación que responden a sus necesidades y a las metas que ella persigue.

\section{Obediencia}

Conjunto de actitudes y conductas que identifican como valor central en la vida de relación el principio de autoridad (sea ésta moral o formal) y la consecuente sumisión y respeto a normas o prescripciones sustentadas en él.

\section{Autoestima}

Conjunto de actitudes y valoraciones de una persona con referencia a sus cualidades y defectos, sus logros y fracasos, así como a su posición social en comparación con los demás.

\section{Planificación}

Conjunto de apreciaciones organizadas y acciones sistemáticas que la persona lleva a cabo acerca de planes y comportamientos futuros con el propósito de obtener determinados objetivos que ella considera valiosos.

\section{Organización}

Disposición para llevar a cabo acciones y regular el comportamiento propio sobre la base de procedimientos caracterizados por destacar el orden, el uso planificado del tiempo y la ubicación precisa de objetos.

\section{Conducta de riesgo}

Comportamiento que puede poner en 
Fernández

peligro la integridad física propia o de otros o exponerla a situaciones que puedan acarrearle problemas de salud o pérdida de imagen ante los demás, todo esto con plena conciencia del peligro. 


\section{ApÉNDICE 2}

\section{ENCUESTA}

\section{Instrucciones:}

Ésta es una encuesta que indaga acerca de lo que usted conoce, piensa y actúa con relación a su sexualidad. La información que usted nos proporcione nos permitirá desarrollar actividades que aborden las inquietudes que con respecto a este tema tienen los estudiantes universitarios.

Le rogamos leer detenidamente cada pregunta y contestar la respuesta que más se acomode a su forma de ser. El cuestionario es completamente anónimo.

\section{Gracias}

\section{I. Área de datos generales}

1. UNIVERSIDAD

2. EDAD

3. FACULTAD

4. CICLO DE ESTUDIOS :

5. SEXO

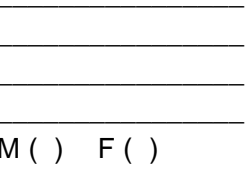

6. ¿Ha recibido algún tipo de información sexual?
¿A través de quiénes?
() familia
() amigos
() libros, revistas especializadas
( ) medios de comunicación masiva, ¿cuáles?

$$
\begin{array}{ll}
\text { ( ) } & \text { tv } \\
\text { ( ) } & \text { radio } \\
\text { ( ) } & \text { revistas, periódicos }
\end{array}
$$

7. ¿Ha recibido algún tipo de educación sexual?

sí ( ) NO ( ) ¿Dónde? (marque la más importante)
( ) colegio
( ) universidad
( ) instituto
( ) otros especifique :

8. Si participó en un curso de Educación Sexual, ¿cuántas horas de duración?

( ) 0 - 5

( ) $6-10$

( ) $11-15$

( ) 16- 20

( ) 21 a más 
Fernández

9. En dicho curso se abordaron:

( ) Aspectos biológicos de la sexualidad

( ) Aspectos psicológicos de la sexualidad

( ) Aspectos sociales de la sexualidad

( ) Otros (especifique) :

\section{II. Área de información psicosocial}

1. ¿Con quién vives?

2. ¿Sales con algún muchacho(a)?
a. Sí
b. No

3. ¿Hace cuánto tiempo?
a. Menos de un mes
b. Uno a tres meses
c. Cuatro a seis meses
d. Siete a doce meses
e. Más de un año

4. ¿Qué otra ocupación tienes además de la universidad?

5. ¿En qué trabaja (trabajaba) tu mamá?

6. ¿En qué trabaja (trabajaba) tu papá?

7. ¿Con quién te criaste de niño?

8. ¿Qué educación tienen tus padres?
a. Primaria incompleta
b. Primaria completa
c. Secundaria incompleta
d. Secundaria completa
e. Superior incompleta
f. Superior completa

$\begin{array}{ll}\text { Mamá } & \text { Papá } \\ (\text { ) } & (\text { ) } \\ (\text { ) } & (\text { ) } \\ (\text { ) } & (\text { ) } \\ (\text { ) } & (\text { ) } \\ (\text { ) } & (\text { ) } \\ (\text { ) } & (\text { ) }\end{array}$


9. ¿Cómo te llevas con tu mamá?

a. Mal

b. Regular

c. Bien

10. ¿Qué tan enojona es tu mamá?
a. Nada
b. Poco
c. Regular
d. Mucho

11. ¿Qué tan enojón es tu papá?
a. Nada
b. Poco
c. Regular
d. Mucho

12. ¿Cuándo tienes un problema personal, lo conversas con tu mamá?
a. No, nunca
b. A veces, depende
c. Sí, siempre

13. ¿Cuándo tienes un problema personal lo conversas con tu papá?
a. No, nunca
b. A veces, depende
c. Sí, siempre

14. ¿Has hablado con tu mamá sobre sexo?
a. Sí
b. No

15. ¿Has hablado con tu papá sobre sexo?
a. Sí
b. No

16. ¿Qué tan frecuentemente has realizado las siguientes actividades en los últimos 12 meses?

Muchas Algunas Pocas Nunca
veces veces veces

a. Haber estado tomado de la mano de un(a) muchacho(a)

b. Haberte masturbado a ti mismo(a)

c. Haber sido masturbado por un(a) muchacho(a)

d. Haber dado o recibido un beso en la boca

i. Haber estado con un(a) muchacho(a) que te haya tocado tus partes íntimas o haberle tocado sus partes íntimas a un(a) muchacho(a) 


\section{Fernández,}

j. Haber tenido relaciones sexuales(haberte acostado con un muchacho[a])

k. Haber tenido ganas de tener relaciones sexuales

17. ¿Qué tanto le has conversado a tu mamá sobre los siguientes temas :
a. Si tener o no relaciones antes de casarse
Nada Casi nada Algunas Muchas
b. El número de hijos que quisieras tener
c. Si usar anticonceptivos
d. La menstruación (regla)
e. Cuándo tener el primer hijo

18. ¿Qué tanto le has conversado a tu papá sobre los siguientes temas? :
a. Si tener o no relaciones antes de casarse
b. El número de hijos que quisieras tener
c. Si usar anticonceptivos
d. La menstruación (regla)
e. Cuándo tener el primer hijo

Nada Casi nada Algunas Muchas

19. ¿Tienes alguna hermana que se haya embarazado antes de casarse?
a. Sí
b. No

20. ¿Tienes algún hermano que haya embarazado a una muchacha antes de casarse?
a. Sí
b. No

21. ¿A qué edad aproximadamente se embarazó por primera vez tu mamá?

22. ¿Estaba soltera?
a. Sí
b. No

23. ¿Has tenido relaciones sexuales?
a. Sí
b. No

24. ¿A qué edad tuviste tu primera relación sexual?

A los años

25. ¿Con quién fue?
a. Un amigo(a)
b. Enamorado(a)
c. Novio(a)
d. Esposo(a) 

e. Un familiar
f. Una mujer casada (no familiar)
g. Una prostituta
h. Empleado(a) doméstic(a)

26. ¿Cuántos años tenía esa persona? años

27. ¿Crees que es demasiado tarde tratar de usar anticonceptivos cuando ya está excitado (a) tu pareja?
a. Sí
b. No

28. ¿Has conversado acerca de anticonceptivos con tu pareja? (la última pareja que tuviste, si no has salido con alguien del sexo opuesto no contestes )
a. Sí
b. No

29. ¿Están de acuerdo tú y tu compañero (a) acerca de quién debe tener la responsabilidad del uso de anticonceptivos? (la última pareja que tuviste, si no has salido con alguien del sexo opuesto no contestes)
a. Sí
b. No

30. ¿Después de la primera vez, volviste a tener relaciones sexuales? (si no has tenido relaciones sexuales no contestes)
a. Sí
b. No

31. ¿Con la misma persona? (si no has tenido relaciones sexuales no contestes )
a. Sí
b. No

32. Esa vez que tuviste tu primera relación sexual, consideraste que podías quedar embarazada o que podrías embarazar a tu pareja? (si no has tenido relaciones sexuales, no contestes )
a. Sí
b. No

33. ¿Me puedes explicar cómo se embaraza una mujer?

34. ¿Hay algo que se pueda hacer para que no se embarace una mujer?
a. Sí
b. No

35. ¿Qué se puede hacer? 


\section{Fernández,}

36. ¿Me puedes decir cómo se usan?

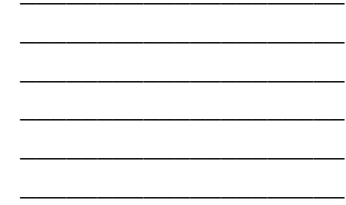

37. ¿Has usado alguno? (si no has tenido relaciones sexuales, no contestes y pasa a la pregunta 42).
a. Sí
b. No

38. ¿Cuál o cuáles son?

39. La primera vez que tuviste relaciones sexuales, ¿tú o tu pareja hicieron algo para evitar el embarazo?
a. Sí
b. No

40. ¿Qué hicieron para evitarlo?

41. ¿En dónde lo consiguieron?

III. Área de conocimientos sobre sexualidad

\section{En las preguntas siguientes marca lo que consideres que es la respuesta correcta: (marque sólo 1)}

42. Dos de las estructuras que corresponden al aparato sexual masculino son:
( ) a. La próstata y el clítoris
( ) b. El útero y los conductos deferentes
( ) c. Los testículos y los conductos deferentes
( ) d. El Monte de Venus y los testículos
( ) e. No sé

43. El lugar donde se lleva a cabo la fecundación, unión del espermatozoide con el óvulo, es en:
( ) a. La zona de los labios menores y el clítoris
( ) b. La parte terminal de las trompas de Falopio 

( ) c. La parte inferior de la vagina
( ) d. Los contornos del ovario
( ) e. No sé

44. Los días más fértiles de la mujer dentro de su ciclo menstrual, son :
( ) a. Alrededor del día 12 al 16 de su ciclo menstrual
( ) b. Los días que dura la menstruación
( ) c. Los cuatro días siguientes a la menstruación
( ) d. Del día 24 al 27 de su ciclo menstrual
( ) e. No sé

45. El período más recomendable para tener hijos es de:
( ) a. Los 15 a los 20 años de edad
( ) b. Los 18 a los 37 años de edad
( ) c. Los 12 a los 18 años de edad
( ) d. Los 20 a los 30 años de edad
( ) e. No sé

46. Dos de las enfermedades sexualmente transmisibles, son:
( ) a. El acné y el sida
() b. La gonorrea y la sífilis
( ) c. La sífilis y la estirilidad
( ) d. La gonorrea y las paperas
( ) e. No sé

47. Las enfermedades sexualmente transmisibles se presentan en:

( ) a. Las personas que acuden frecuentemente a baños públicos

( ) b. Todas las personas que tengan contacto sexual con prostitutas

( ) c. Cualquier persona que tenga un contacto sexual con una persona infectada

( ) d. Las personas que tienen contacto sexual con homosexuales

( ) e. No sé

48. La masturbación:
( ) a. Favorece el retraso mental de quien la practica
( ) b. Es una actividad saludable en la vida sexual del individuo
( ) c. Impide el crecimiento físico del individuo
( ) d. Favorece la aparición de acné en los adolescentes
( ) e. No sé

49. Medidas para prevenir enfermedades sexualmente transmisibles
( ) a. Seleccionar de manera consciente a la pareja
( ) b. Asear los genitales después del acto sexual
( ) c. Utilizar el preservativo o condón
( ) d. Todas las anteriores
( ) e. No sé 


\section{Fernández,}

50. Los métodos anticonceptivos más eficaces y adecuados para los adolescentes que tienen relaciones sexuales de vez en cuando, son:
( ) a. La combinación de condón y óvulo (espermicidas)
( ) b. Los inyectables y el dispositivo intrauterino
( ) c. El retiro y control de la temperatura vaginal
( ) d. El ritmo y la ducha vaginal
( ) e. No sé

Instrucciones: Manifieste su opinión acerca de las siguientes preguntas, marcando con un aspa $(\mathrm{X})$ la alternativa de respuesta correspondiente:

51. ¿Se puede embarazar una mujer aunque no se excite Sí NO NO SÉ durante el acto sexual?

52. ¿Se puede embarazar una mujer por usar el baño público?

53. ¿Una forma de prevenir el embarazo es lavarse bien sus partes después de tener relaciones?

54. ¿Se puede embarazar una mujer aunque el hombre saque el pene (su miembro) antes de eyacular?

55. ¿Se puede embarazar una mujer aunque sólo tenga relaciones sexuales de vez en cuando?

56. ¿Se puede embarazar una mujer la primera vez que tenga relaciones?

57. ¿Se puede embarazar a una mujer por meterse a nadar a una piscina?

58. ¿Crees que si una mujer toma pastillas para evitar el embarazo, ya nunca podrá tener hijos?

59. ¿Si se están tomando pastillas anticonceptivas se deben tomar a diario aunque no se tengan relaciones sexuales muy seguido?

60. ¿Es cierto que si una mujer se toma una pastilla anticonceptiva después de haber tenido relaciones sexuales, no se embaraza?

61. ¿Puede servir un sólo condón para dos o tres relaciones sexuales?

62. ¿Crees que los métodos para evitar el embarazo causan enfermedades en las mujeres? 
63. ¿Qué tanto les has conversado a tus amigos(as) de los siguientes temas?

Muchas Algunas Pocas Nunca
veces veces veces
a. La menstruación (regla)
b. El número de hijos que quisieras tener
c. Si usar o no métodos anticonceptivos
d. Cuáles métodos anticonceptivos usar

64. ¿De tus amigos(as) cuántos han tenido relaciones sexuales alguna vez?
( ) a. Todos(as)
( ) b. La mayoría
( ) c. Pocos(as)
( ) d. Uno(a)
() e. Ninguno(a)
( ) f. No sé

65. De tus amigos(as) que tienen relaciones sexuales, ¿cuántos(as) de ellos(as) o sus parejas hacen algo para no embarazarse?
( ) a. Todos(as)
( ) b. La mayoría
( ) c. Pocos(as)
( ) d. Uno(a)
( ) e. Ninguno(a)
() f. No sé

66. ¿Cuántas de tus amigas que tú sepas, han estado embarazadas?
( ) a. Todos(as)
( ) b. La mayoría
( ) c. Pocos(as)
( ) d. Uno(a)
( ) e. Ninguno(a)
( ) f. No sé

67. ¿Cuántos de tus amigos que tú sepas, han embarazado a una muchacha?
( ) a. Todos(as)
( ) b. La mayoría
( ) c. Pocos(as)
( ) d. Uno(a)
( ) e. Ninguno(a)
( ) f. No sé 


\section{Fernández,}

\section{IV. Área de aspectos afectivos}

\section{Instrucciones: marque con un aspa $(X)$ la alternativa de respuesta que se asemeje a su forma de ser}

Siempre $\begin{gathered}\text { Muchas Pocas Nunca } \\ \text { veces veces }\end{gathered}$

68. ¿Te da pena decir NO cuando te invitan a algún lado?

69. ¿Tratas de no hacer preguntas por miedo a que suenen tontas?

70. ¿Te daría pena decirle a un amigo(a) que estás ocupado(a) y no puedes atenderlo(a)?

71. ¿Te da pena pedir que te regresen cosas que has prestado?

72. ¿Te ayuda a resolver problemas el caerle bien a la gente?

73. ¿Puedes conseguir lo que quieras si le caes bien a la gente?

74. ¿Si tienes éxito dependerá de lo agradable que eres?

75. ¿Crees que tener un bebé ahora, arruinaría tu vida?

76. ¿Piensas que tener un bebé te haría sentir más contento(a)?

77. ¿Sientes que es mejor dejar que alguien te diga lo que tienes que hacer?

78. ¿Crees que si tuvieras un bebé, no te sentirías tan solo(a)?

79. ¿Duda un buen hijo de la palabra de su madre?

80. ¿Haces cosas a veces aunque tus papás (o sustitutos) no estén de acuerdo?

81. ¿Te da pena decirles a los vecinos que dejen de hacer ruido?

82. ¿Obedeces siempre a tus papás (o sustitutos)?

83. ¿Te impones cuando crees que tienes la razón?

84. ¿Crees que si consigues un buen empleo es una cuestión de suerte?

85. ¿Tus papás (o sustitutos) o tu pareja te dicen casi siempre lo que debes hacer?

86. ¿Pone peros un buen hijo a las órdenes de sus padres?

87. ¿Has pensado bien lo que esperas de tu vida familiar cuando seas mayor?

88. ¿Te organizas para poder hacer todo lo que necesitas hacer?

89. ¿Sabes qué llegarás a ser en unos años?

90. ¿Te gusta planear tu tiempo libre?

91. ¿Te es difícil planear tus actividades (lo que tienes que hacer)? 
92. ¿Has pensado qué vas a hacer en el futuro?

93. ¿Eres organizado?

94. ¿Te gusta hacer cosas que impliquen peligro?

95. ¿Te gusta tomar riesgos, sin pensar en lo que pueda pasar?

96. ¿Te cuesta trabajo hacer planes de lo que vas a hacer?

97. ¿Pierdes mucho tiempo por falta de organización?

98. ¿En tu vida puedes escoger lo que quieres hacer?

99. ¿Lo que haces depende de ti?

100. ¿Sabes de qué depende lo que pasa en tu vida?

101. ¿Sabes por qué te pasan las cosas que te pasan?

102. ¿Sientes que tienes control sobre lo que te ocurre en la vida?

103. ¿Te consideras una persona valiosa?

104. ¿Piensan los demás que eres guapo(a)?

105. ¿Le caes bien a los(las) jóvenes de tu edad?

106. ¿Eres más querido(a) que la mayoría de las personas?

107. ¿Eres seguro(a) de ti mismo(a)? 